\title{
Neurochemistry of Visual Attention
}

\author{
Denise Elfriede Liesa Lockhofen* and Christoph Mulert \\ Center for Psychiatry and Psychotherapy, Justus-Liebig University, Hessen, Germany
}

\section{OPEN ACCESS}

Edited by:

Paul Newhouse,

Vanderbilt University, United States

Reviewed by:

Christiane Thiel,

University of Oldenburg, Germany

Robert Warren Gould,

Wake Forest School of Medicine,

United States

*Correspondence:

Denise Elfriede Liesa Lockhofen Denise.E.Lockhofen@psychiat.med. uni-giessen.de

Specialty section: This article was submitted to

Neuropharmacology,

a section of the journal

Frontiers in Neuroscience

Received: 18 December 2020

Accepted: 12 April 2021

Published: 05 May 2021

Citation:

Lockhofen DEL and Mulert C (2021) Neurochemistry of Visual

Attention.

Front. Neurosci. 15:643597. doi: 10.3389/fnins.2021.643597
Visual attention is the cognitive process that mediates the selection of important information from the environment. This selection is usually controlled by bottom-up and top-down attentional biasing. Since for most humans vision is the dominant sense, visual attention is critically important for higher-order cognitive functions and related deficits are a core symptom of many neuropsychiatric and neurological disorders. Here, we summarize the importance and relative contributions of different neuromodulators and neurotransmitters to the neural mechanisms of top-down and bottom-up attentional control. We will not only review the roles of widely accepted neuromodulators, such as acetylcholine, dopamine and noradrenaline, but also the contributions of other modulatory substances. In doing so, we hope to shed some light on the current understanding of the role of neurochemistry in shaping neuron properties contributing to the allocation of attention in the visual field.

Keywords: visual attention, attentional selection, neurochemistry, psychopharmacology, neuromodulator

\section{INTRODUCTION}

\section{Definition of Visual Attention}

The term "visual attention" refers to cognitive processes that allow us to selectively process the vast amount of information we are confronted with every day. Since the capacities of the perceptual system are limited, focusing on a certain aspect of the visual field enables us to prioritize relevant information and ignore irrelevant information. Even though there are many definitions of attention, the following review will mainly be concerned with visuospatial selective attention.

\section{Bottom-Up and Top-Down Attention}

This biasing of input is implemented through different types of attention. One of the most common distinctions is made between top-down and bottom-up attention (Corbetta and Shulman, 2002). Top-down refers to the voluntary guidance of attention by internal goals, whereas bottom-up attention refers to the involuntarily capture of attention by salient events in the environment.

Abbreviations: 5-HT, 5-hydroxytryptamine (serotonin); ACh, acetylcholine; ADHD, attention-deficit-hyperactivitydisorder; BG, basal ganglia; BOLD, blood-oxygen-level-dependent; CHT, choline transporter; COMT, catechyl-Omethyltransferase; DA, dopamine; DAN, dorsal attention network; DAT, DA transporter; DBH, dopamine-beta-hydroxylase; DMN, default mode network; FCPN, fronto-parietal control network; FEF, frontal eye field; fMRI, functional magnetic resonance imaging; GABA, gamma-aminobutric acid; IPS, intraparietal sulcus; LC, locus coeruleus; mAChR, muscarinic ACh receptor; MRS, magnetic resonance spectroscopy; NA, noradrenaline; nAChR, nicotinic ACh receptor; NMDA, N-methylD-aspartate; PET, positron-emission-tomography; PFC, prefrontal cortex; SNR, signal-to-noise-ratio; SOA, stimulus-onsetasynchrony; tDCS, transcranial direct current stimulation; TMS, transcranial magnetic stimulation. 
These terms describe if attention is allocated based on events in the sensory periphery (bottom-up) or from higher cortical areas (top-down). Both attention modes have been associated with distinct neural processes, but seem to be closely connected (Katsuki and Constantinidis, 2014). For example, it was found that top-down beta band influences causally increased bottom-up gamma-band influences from early visual areas (Richter et al., 2017). However, the apparant dichotomy of top-down and bottom-up attention has been challenged recently, since evidence suggests that there might be other factors controlling visual selection, such as reward-based history effects (Awh et al., 2012; Failing and Theeuwes, 2018). Together, these processes modulate neural activity within the visual system and thus shape how we perceive our environment. It has to be kept in mind though that visual attention and working memory processes are difficult to separate and highly interactive (Awh et al., 2006; Theeuwes et al., 2009).

\section{Focus and Motivation of Review}

Visual attention is an important component of higher-level cognition, particularly in humans for whom vision is the dominant sense. Thus, deficits in visual attentional processing are a core symptom of many neurological and neuropsychiatric disorders. In recent years, there has been an ever-growing number of studies dedicated to the field of visual attention processing, especially to the important question of underlying mechanisms. This increasing interest is supported by recent advances in technology. Electrophysiological and neuroimaging methods have provided new insights into the human brain while it is engaged in cognitive work (He et al., 2011). Non-invasive stimulation methods, like transcranial magnetic stimulation (TMS) and transcranial direct current stimulation (tDCS), have been used to influence the excitability of cortical tissues and to investigate the cognitive functions of brain regions (Sparing and Mottaghy, 2008). In addition, magnetic resonance spectroscopy (MRS) measures the concentration of metabolites in different tissues and allows for the in vivo study of biochemical processes in the brain (Tognarelli et al., 2015). However, despite the growing interest in the topic and the development of new techniques, there are still many open questions concerning the mechanistic basis of visual attention (Moore and Zirnsak, 2017). Until now, studies targeting the neurophysiology or neurochemistry behind attentional processing have focused on top-down attentional processes. It can be assumed that bottom-up attention also modulates neural activity within the visual system, but this mechanism is comparably less well understood (Noudoost et al., 2010; Moore and Zirnsak, 2017; Thiele and Bellgrove, 2018). This is unfortunate, because several neuropsychiatric disorders have been linked to deficits in bottom-up attentional processing, such as schizophrenia (Javitt, 2009; Neuhaus et al., 2011) and ADHD (Schneidt et al., 2018). In contrast to earlier works, we want to give a more complete overview of the neurochemical influences on both aspects of visual attention. Furthermore, we aim to include neuromodulators and neurotransmitters that other reviews have so far neglected. In doing so, we hope to shed some light on aspects of visual attentional processing that have not yet been thoroughly investigated.

\section{NEURAL BASIS OF ATTENTIONAL PROCESSING}

\section{Brain Regions Involved in (Top-Down and Bottom-Up) Visual Attention}

Visual attention is by definition a selective process. It facilitates the processing of information based on their visual saliency or inherent goals, while irrelevant stimuli are filtered out. Neurophysiological and neuroimaging studies have provided valuable information about the brain regions involved in this filtering process. Generally, it is believed that the influence of attention increases along a cortical hierarchy, characterized by expanding size and complexity of receptive fields (Serences and Yantis, 2006). However, early attentional effects are already detectable at V1 (Katsuki and Constantinidis, 2014). From there, bottom-up processing of visual information ascends to higher cortical areas through two major pathways. The ventral pathway, comprising posterior visual areas (V1-V4), the inferior temporal cortex and the ventral prefrontal cortex, is assumed to deal with object- and feature-based visual processes. The dorsal pathway on the other hand is supposed to deal with spatial- and movement-related processes and includes V1, $\mathrm{V} 2$, and V3, middle temporal regions, the posterior parietal cortex and the dorsolateral prefrontal cortex (Mishkin and Ungerleider, 1982; Ungerleider and Haxby, 1994; Katsuki and Constantinidis, 2014). By contrast, the top-down selection of visual information is supported by prefrontal and parietal areas and exerts its influence primarily through feedback connections. Particularly brain regions associated with oculomotor or gaze function, such as the frontal eye fields (FEF) and the intraparietal sulcus (IPS), seem to be involved in voluntary attentional control (Noudoost et al., 2010; Meehan et al., 2017; Thiele and Bellgrove, 2018).

\section{Computational Theories of Visual Attention}

Computational theories of attention provide a closer look at the neural mechanisms by which relevant information are filtered from the environment (Koch and Ullman, 1985; Itti and Koch, 2001). They propose that bottom-up attention is implemented through a mechanism, which directs attention to the most salient stimulus in the visual field. Therefore, it is assumed that the basic visual features supporting the selection of a certain stimulus (e.g., orientation, luminance or color) are represented in separate feature maps, which are then combined into a topographically oriented global saliency map. Based on a winner-take-all-mechanism attention increases neuronal activity for the winning neuron population and suppresses all competing populations. Thus, attention is directed to the spot on the salience map which shows the most activation (Katsuki and Constantinidis, 2014). However, attention allocation is not only determined by stimulus salience 
but also by internal goals. This led to the postulation of a priority map, which is supposed to integrate top-down and bottomup factors (Serences and Yantis, 2006; Bisley and Goldberg, 2010). The idea of a priority map simultaneously modulated by both processes is supported by functional magnetic resonance imaging (fMRI) research showing that bottom-up and top-down attention increase activation in an overlapping frontoparietal brain network (Corbetta and Shulman, 2002; Katsuki and Constantinidis, 2012, 2014).

\section{Attentional Effects on Neuronal Activity}

On the neural level, attention modulates the acitivity of neurons or neuron populations representing an attended location or feature by increasing their signal-to-noise-ratio (SNR; Noudoost et al., 2010; Paneri and Gregoriou, 2017; Sapountzis and Gregoriou, 2018). One way in which attention strengthens the selected signals is by modulation of the neuron's firing rate. Another important effect of attention is a decrease in the correlated variability of visual neurons, which might be an even more significant factor with respect to general reductions in SNR than the modulation of firing rates (Cohen and Maunsell, 2009; Mitchell et al., 2009; Deco and Hugues, 2012; Paneri and Gregoriou, 2017). Additionally, attention might lead to frequency specific modulations of local oscillatory activity at different stages of visual processing (Gregoriou et al., 2015). These modulations include rhythmic synchronizations in the gamma band range $(30-60 \mathrm{~Hz})$ which might result in a more effective processing (Murthy and Fetz, 1994; Fries, 2005, 2009; Deco and Thiele, 2009; van Es and Schoffelen, 2019). Support for this assumption comes from neurophysiological studies that demonstrate long-range gamma coupling between visual neurons processing an attended stimulus (Gregoriou et al., 2009; Bosman et al., 2012; Grothe et al., 2012). Thus, competition between representations during attentional selection might be resolved by modulations of firing rate and inter-neuronal variability, but also by coordinated oscillatory activity (Paneri and Gregoriou, 2017). How these changes are brought about is still not completely clear. One option would be the involvement of neuromodulators.

\section{NEUROMODULATION}

\section{General Information}

Neuromodulation describes the alteration of neuronal and synaptic properties by neurons or substances released by neurons (Katz and Calin-Jageman, 2008). A wide variety of substances, including neurotransmitters, biogenic amines and neuropeptides can act as neuromodulators (Noudoost and Moore, 2012; Nadim and Bucher, 2014; Moore and Zirnsak, 2017). While there is no exact definition of the term "neuromodulator," Picciotto et al. (2012) describe them as "any kind of neurotranmission that is not directly excitatory [...] or inhibitory [...]" (p.1, refering to Siggins, 1979; Ito and Schuman, 2008). The human neuromodulatory system includes noradrenergic, serotonergic, dopaminergic and cholinergic projections, which are thought to provide a foundation for many higher cognitive functions, such as attention, decision-making, emotion and goal-directed behavior (Avery and Krichmar, 2017). Neuromodulatory actions are generally mediated by G-protein-coupled receptors and affect ion channels or other membrane proteins. Thereby, neuromodulators can change intrinsic firing properties and alter the synaptic strength of neurons, as well as modify short-term and long-term plasticity (Gu, 2003; Sakurai and Katz, 2009; Picciotto et al., 2012; Nadim and Bucher, 2014). It has to be kept in mind though, that because of the complexity of neuromodulatory effects, the non-linear dynamics of neuromodulators and the simultaneous synaptic presence of several neuromodulators, the consequences for specific cortical processes, like visual attention, are difficult to comprehend (Nadim and Bucher, 2014).

\section{Neuromodulation of Visual Attention}

Shifts in behavioral states (from sleep to wakefulness or from inattentive to vigilant) are connected to changes in global brain activity. These changes are at least partly controlled by neuromodulators (Lee and Dan, 2012). However, since attentional processes, such as top-down attention, were considered to be highly specific, whereas the actions and projections of most neuromodulators were not, their involvement in regulating selective attention remained controversal (Mesulam et al., 1986; Sarter et al., 2009). Only recently, it has been assumed that the global mechanisms governing cortical states may also operate on a local scale, for example during visual selective attention (Harris and Thiele, 2012; Rabinowitz et al., 2015; Engel et al., 2016). This assumption was supported by studies demonstrating that the same neuromodulators known to act on a brain-wide scale also modulate attentional effects (Zaborszky and Duque, 2003; Herrero et al., 2008; Harris and Thiele, 2012; Noudoost and Moore, 2012). For example, the neurotransmitter acetylcholine (ACh) has been implicated in vigilance and attention, as well as in the regulation of global brain states (Lee et al., 2005). Applying ACh to cells in primate $\mathrm{V} 1$, as well as enhancing ACh activity with cholinesterase inhibitors (donezepil) in humans seems to evoke neuronal effects similar to those of attention (Roberts et al., 2007; Gratton et al., 2017). Furthermore, attention can stabilize network states and decrease interneuronal correlation (Deco and Hugues, 2012). Interestingly, a decrease in neural variability is also found when stimulating the basal forebrain in rats, assumed to be associated with a local activation of ACh receptors (Goard and Dan, 2009). These and other similarities between attention and cholinergic activation have led to the suggestion that the neuromodulator ACh might be involved in attentional processing (Lee and Dan, 2012).

\section{NEUROMODULATORS}

Neuromodulators most often implicated in attentional processes include ACh and dopamine (Noudoost and Moore, 2011; Froemke, 2015; Thiele and Bellgrove, 2018). However, in the following section we will also review other important neuromodulators and their influence on voluntary and involuntary visual attention. 


\section{Acetylcholine General}

$\mathrm{ACh}$ is an important neurotransmitter at the neuromuscular junction. In the brain its actions are primarily neuromodulatory (Picciotto et al., 2012). While ACh is synthesized in several different nuclei, its most important source is the basal forebrain. From there cholinergic projections innervate neocortex, hippocampus and amygdala (Mesulam et al., 1983; Woolf, 1991; Thiele, 2013). ACh receptors are typically categorized based on their binding capacity for muscarine and nicotine and thus divided into metabotropic muscarinic receptors (mAchRs) and ionotropic nicotinic receptors ( $\mathrm{nAChRs)}$. Both receptor types show a widespread distribution within the nervous system (Gotti et al., 2006; Thiele, 2013) and there is evidence that they are both involved in attentional control (Noudoost and Moore, 2011). ACh has been implicated in attentional processes for quite a long time (Bartus et al., 1982; Zaborszky et al., 2002; Weinberger, 2007; Sarter et al., 2009; Newman et al., 2012; Carcea and Froemke, 2013; Ballinger et al., 2016). It is assumed to enhance attentional effects in the visual cortex by improving neuronal tuning (Sajedin et al., 2019) and modulating the spatial properties of receptive fields (Roberts et al., 2007; Gratton et al., 2017). Additionally, ACh seems to alter the covariance structure of cortical networks and to increase their coding capacity (Minces et al., 2017; Thiele and Bellgrove, 2018). Whereas earlier studies assumed that the cholinergic system would lack spatial and functional specificity (Mesulam et al., 1986; Sarter et al., 2009), recent findings argue that the spatial specificity of cholinergic projections is better than previously believed (Thiele, 2013; Wu et al., 2014; Unal et al., 2015; Zaborszky et al., 2015, 2018; Jiang et al., 2016; Gielow and Zaborszky, 2017). In this context, it was demonstrated that ACh not only shows slow tonic activity (Manns et al., 2000; Lee et al., 2005), but also precise phasic activities, associated with cue detection performance in attention tasks (Parikh and Sarter, 2008; Sarter et al., 2009; Gritton et al., 2016).

\section{Effects of ACh Modulation on Visual Attention}

Most earlier studies examined rodents and non-human primates to establish that attention allocation leads to changes in neuronal activity throughout the visual system. In monkeys, the application of ACh augmented their responses to attended stimuli, while the application of an mAchR antagonist (scopolamine) reduced the modulatory effect of attention (Herrero et al., 2008). In humans, the acute cognitive effects of $\mathrm{nAChR}$ agonist nicotine on attention but also on sensory processing and memory are well established (Heishman et al., 2010; Hahn, 2015; Hahn et al., 2020). Evidence for ACh involvement in attentional modulation comes from a variety of studies using different methodologies. Using magnetic resonance spectroscopy, Lindner et al. (2017) measured choline as an indirect marker of $\mathrm{ACh}$ availability in the brain. By measuring choline levels in the parietal cortex during a visuospatial attention task, they found direct evidence for the involvement of cholinergic systems in human visual attention. In a doubleblind, placebo-controlled crossover fMRI study Ricciardi et al. (2013) assessed cholinergic effects on brain connectivity and blood-oxygen-level-dependent (BOLD) signal variability during a visual selective attention task (matching task with superimposed faces and houses). They found that cholinergic enhancement by physostigmine (acetylcholinesterase inhibitor) improved task performance as well as reduced BOLD signal variability and functional connectivity between ventral visual processing areas and task-relevant regions. These findings were concluded to be in line with the assumption that cholinergic modulation enhances neural efficiency reflected by less BOLD signal variability in visual regions (Ricciardi et al., 2013). Research targeting the genetics of cholinergic influence on visual attention investigated the choline transporter (CHT), which is important for the synthesis and release of ACh (Sarter et al., 2016). The authors found that genetically reduced CHT activity leads to poorer top-down attentional control and more attentional distraction, whereas elevated levels of CHT may increase resistance to distraction. Moreover, it was found that ACh modulates neural oscillations during attentional processing (Bauer et al., 2012; Howe et al., 2017). In rats, for example, detection of visual cues was associated with phasic $\mathrm{ACh}$ release and increases in high and low frequency power. In addition, $\mathrm{nAChR}$ and $\mathrm{mAChR}$ antagonists (mecamylamine, telencepine) reduced power in the high gamma frequency, most likely related to cue-triggered reorienting effects (Howe et al., 2017). In humans, the cholinergic agonist physostigmine has been shown to enhance visual attention effects on lowlevel alpha and beta oscillations (Bauer et al., 2012). After establishing that $\mathrm{ACh}$ plays a major role in modulating attentional processes, the following section will try to dissociate the contributions of nicotinic and muscarinic receptor types to this modulatory effect.

\section{Dissociable Effects of nAChR and mAChR}

Both, the $\mathrm{nACh}$ and the $\mathrm{mACh}$ receptor allow ACh to modulate electrical activity of cortical neurons and to affect intracellular signaling (Thiele, 2013; Yakel, 2013). In addition, both have been implicated in higher cognition, particularly in attention and memory (Friedman, 2004; Green et al., 2005; Sarter and Parikh, 2005; Ellis et al., 2006).

Concerning nicotinic involvement in visual attention, it was found that in human participants nicotine (administered as NICORETTE polacrilex gum) improved attentional reorienting in a visuospatial cued detection task by a reduction of neural activity in parietal brain regions of non-smoking participants, measured by fMRI (Thiel et al., 2005). In another fMRI study, Hahn et al. (2009) found that nicotine (administered as transdermal patch) reduced reaction times specifically for selective attention tasks (compared with a divided attention task), while also reducing BOLD activity in several cortical and subcortical regions and increasing deactivations within the default mode network. Thus, the effects of nicotine on attention seem to be task-dependent with a stronger impact on simple detection tasks, probably induced by an enhanced functional efficiency and a downregulation of task-independent default activity (Hahn et al., 2009). Furthermore, applying a nicotine antagonist (Mecamylamine) led to disturbances in visual attention and fine motor 
tasks, which could be reversed by the administration of transdermal nicotine (Alvarez-Jimenez et al., 2018). Using a CombiTVA paradigm, Vangkilde et al. (2011) showed that nicotine (administered as Nicotinelle polacrilex gum) lowers the perceptual threshold, speeding up short-term memory transfer, but slowing down subsequent information processing and weakening top-down selective attention. In addition, it was demonstrated that normal variation in a nicotinic receptor gene modulated visuospatial attention, but dopamine gene variability did not (Greenwood et al., 2005; Parasuraman et al., 2005). However, low doses of an nAChR antagonist (mecamylamine) did not seem to affect spatial selective attention, stimulus detection or visual information processing (Yuille et al., 2017).

Besides, there is also evidence of muscarinic involvement in attentional modulation. In rodents, mACh transmission influences visual processing in V1 (Kang et al., 2014), improving neural sensitivity and increasing long-term responsiveness (Gu, 2003; Kang and Vaucher, 2009; Kang et al., 2014). Using iontophoretic pharmacological analysis and single-cell recordings in V1 neurons of macaque monkeys performing a top-down spatial attention task, it was found that low doses of ACh enhanced attentional modulation in V1 neurons, while applying scopolamine (mACh antagonist) reduced attentional modulation and mecamylamine (nACh antagonist) had no effect (Herrero et al., 2008). In humans, Laube et al. (2017) found that the mAChR antagonist scopolamine modulated top-down attentional control processes during a contingent capture task by reducing an EEG component associated with active suppression of irrelevant distractors. Additionally, Ellis et al. (2006) showed that muscarinic (scopolamine), but not nicotinic (mecamylamine) blockade reduced performance in sustained attention measured by digit vigilance and rapid visual information processing tasks.

However, there is also the idea that nicotinic and muscarinic influences might have differential effects, but work synergistically to shape attentional processing (Hasselmo, 2005; Ellis et al., 2006; Greenwood et al., 2009; Dasilva et al., 2019). For example, it was proposed that $\mathrm{ACh}$ would enhance thalamocortical transmissions through nicotinic receptors, boosting bottomup inputs. Top-down attentional effects, on the other hand, would be reduced by muscarinic inhibition (Hasselmo, 2005; Greenwood et al., 2009). These differences in cholinergic actions across brain regions might be supported by the different expression profiles of nicotinic and muscarinic receptors from primary sensory to higher cortical areas (Galvin et al., 2018). For example, it was found that in macaque early visual areas (V1) mACh receptors were predominantly expressed by gamma-aminobutric acid (GABA) ergic cells while in higher regions they also occured on pyramidal cells. In V1 nicotinic $\beta 2$ receptors are expressed presynaptically on thalamocortical cells (Disney et al., 2007; Galvin et al., 2018), whereas in higher cortical regions, $\mathrm{nACh}$ receptors are expressed on glutamatergic inputs to layer $\mathrm{V}$ cells as well as on layer $\mathrm{V}$ interneurons and pyramidal neurons (Poorthuis et al., 2013). Furthermore, mACh and nACh receptors showed celltype specific activity by promoting attentional control signals through muscarinic receptors in broad spiking cells and through muscarinic and nicotinic cells in narrow spiking cells (Dasilva et al., 2019).

\section{ACh Effects on Bottom-Up and Top-Down Visual Attention}

It is believed that $\mathrm{ACh}$ has a greater effect on top-down attentional modulation than on bottom-up cue detection (Rokem et al., 2010; Galvin et al., 2018). The cholinesterase inhibitor donezepil selectively improved performance in long SOA trials of a spatial cueing task, thus, enhancing voluntary attention, without affecting involuntary attention. Therefore, it seems likely that top-down and bottom-up attention rely on "different neurochemical mechanisms" (Rokem et al., 2010). A recent study used a contingent capture paradigm and the muscarinic receptor antagonist scopolamine to test the involvement of muscarinic receptor activation in the modulation of top-down attentional control. While scopolamine did not affect early visual featureenhancement or attentional capture by task-relevant features, it did reduce a measure associated with active suppression of distractors, pointing toward a cholinergic modulation of topdown attentional control (Laube et al., 2017). Other studies found that an increase in ACh seems to augment visual attention through an increase of activity in visual regions and a reduced top-down biasing of sensory information (Bentley et al., 2004; Vangkilde et al., 2011). Thus, apart from the influence of $\mathrm{ACh}$ on voluntary attentional control, there is also some evidence of cholinergic influence on bottom-up attention. Studies examining Parkinson's disease patients have demonstrated the importance of thalamic cholinergic integrity for bottom-up attentional mechanisms (Kim K. et al., 2017). Animal and human studies on bottom-up attention show that attentional orienting to peripheral cues is supported by cholinergic activity in the basal ganglia (Voytko et al., 1994; Witte et al., 1997; Murphy and Klein, 1998). A study with nonhuman primates indicates that covert attentional orienting might rely on muscarinic cholinergic activity in the intraparietal cortex (Davidson and Marrocco, 2000). Furthermore, it was found that ACh enhances the response to external sensory information while reducing background noise (Hasselmo and McGaughy, 2004; Hasselmo, 2005). This sharpening of visuospatial representations might favor bottom-up attentional processes. Interestingly, it seems that cholinergic effects on top-down and bottom-up attention are not incompatible. As already mentioned, top-down and bottom-up effects of ACh might rely on the interplay between muscarinic (top-down) and nicotinic (bottom-up) ACh receptors (Hasselmo, 2005; Greenwood et al., 2009). In addition, there is evidence that the two attentional processes might be dissociated by temporal ACh release properties. Whereas bottom-up attention involves phasic ACh release in interaction with thalamocortical circuits (Gritton et al., 2016; Sarter and Lustig, 2019), top-down attention is supported by longer-timescale cholinergic modulation of right fronto-parietal circuity (Paolone et al., 2010; St. Peters et al., 2011; Sarter et al., 2016; Sarter and Lustig, 2019). This is in line with the assumption that cholinergic activity establishes biases based on the interaction of top-down and bottom-up processes that 
synergistically modulate stimulus representation. Furey et al. (2008) for example demonstrated that ACh alters the salience of the attended stimulus and its competing stimuli, influencing top-down as well as bottom-up processing. The finding that one neuromodulator might influence voluntary as well as involuntary attentional processes is consistent with the idea that both processes are closely connected (Katsuki and Constantinidis, 2014). In this context, Kanamaru and Aihara (2019) proposed a network in which top-down ACh can modulate and support bottom-up inputs by increasing the firing rate and changing the response function of visual neurons, further emphasizing the idea that ACh enhances the processing of attended stimuli (Gratton et al., 2017).

\section{Summary}

$\mathrm{ACh}$ is the neuromodulator that has been most often implicated in attention. It also plays an important role in the processing of visual attention (Ricciardi et al., 2013; Sarter et al., 2016; Lindner et al., 2017; Galvin et al., 2018) and might be involved in the modulation of related brain oscillations (Bauer et al., 2012; Howe et al., 2017). Both, nicotinic and muscarinic receptor types, influence attentional processing (Ellis et al., 2006; Thiele, 2013; Laube et al., 2017; Alvarez-Jimenez et al., 2018; Hahn et al., 2020). However, the specific roles of nicotinic and muscarinic activation are not yet fully understood. It is hypothesized that they have differential effects on attentional processes, but work synergistically (Hasselmo, 2005; Greenwood et al., 2009) by implementing the influences generated by top-down and bottomup signals (Furey et al., 2008; Sarter et al., 2016; Gratton et al., 2017; Kanamaru and Aihara, 2019).

\section{Dopamine General}

Dopamine (DA) is a monoamine neurotransmitter, synthesized in the ventral tegmental area and the substantia nigra of the brain (Juárez Olguín et al., 2016). Unlike ACh and other substances, DA does not act as a fast ionotropic neurotransmitter, but seems to mainly influence other receptor channels (Yang and Seamans, 1996; Seamans and Yang, 2004; Vitay and Hamker, 2007). There exist five subtypes of DA receptors: D1, D2, D3, D4, and D5, which are divided into two subclasses, D1-like receptors (D1 and D5) and D2-like receptors (D2, D3, D4; Ayano, 2016). Dopaminergic neurons are widely distributed, in the central nervous system and in the periphery, where they are necessary for the maintenance of many physiological processes. In the brain, the dopaminergic systems play an important role in the neuromodulation of cognitive functions, motor control, motivation, reward, attention and learning. However, DA seems to be especially relevant when it comes to cognitive control and executive function (Floresco and Magyar, 2006; Cools, 2016). Thus, unbalanced activity or dopaminergic dysfunction has been associated to the pathophysiology of several psychiatric and neurodegenerative disesases, such as schizophrenia, mood disorders, obsessive compulsive behavior, autism spectrum disorders, attention deficit-hyperactivity disorder, Tourette's syncrome, substance dependency and Parkinson's disease (Ayano, 2016).

\section{Effects of DA Modulation on Visual Attention}

A dopaminergic role in reward anticipation, reward prediction and learning is already well established (Schultz, 1998; Schott et al., 2008; Steinberg et al., 2013; Thiele and Bellgrove, 2018). Therefore, it is not surprising that the effect of DA on visual attention has been connected to reward processing. For example, it was suggested that visual processing is influenced by the amount of reward associated to a stimulus and that this association is modulated by dopaminergic signals (for review see: Vitay and Hamker, 2007). According to the "incentive salience" hypothesis of Berridge and Robinson (1998) DA influences the visual representations of reward-associated stimuli and makes them more salient. In line with this finding, it was shown that DA is involved in reward-driven modulations of attentional control. For example, incentive reward enhances activity in a network closely associated with DA release and attention (Engelmann et al., 2009). Consistently, it was found that DA improves the signal-to-noise-ratio of neurons at downstream processing sites (Kroener et al., 2009; Pessoa, 2015; Vander Weele et al., 2018), indicating that dopaminergic modulation provides a mechanism by which reward "sharpens" attentional control, thereby enhancing the processing efficiency in cortical and subcortical regions (Failing and Theeuwes, 2017). However, attention and reward are difficult to dissociate (Maunsell, 2004; Peck et al., 2009; Noudoost and Moore, 2012) and there is also evidence that DA signals salient stimuli in absence of reward (Horvitz, 2000).

Possibly independent from its role in reward, DA seems to be central for the processing of attention (Nieoullon, 2002). Prefrontal cortex (PFC) projections of DA-producing neurons in the ventral tegmental area and in the substantia nigra seem to be closely related to several aspects of attention, from inhibitory control to sustained and selective attention (Briand et al., 2007; Noudoost and Moore, 2011; Chandler et al., 2014; Clark and Noudoost, 2014; Ranganath and Jacob, 2016; Shalev et al., 2019). Moreover, it is assumed that the PFC represents the main source of top-down signals biasing attentional selection in early visual areas (Paneri and Gregoriou, 2017; Mueller et al., 2020). Interestingly, optimal PFC functioning seems to rely on moderate D1 receptor stimulation, as well as on the stimulation of noradrenergic $\alpha_{2 A}$ receptors (Arnsten and Pliszka, 2011).

However, the PFC is not the only brain region associated with dopaminergic modulation of attention. DA is also an important determinant of basal ganglia (BG) function-a brain region that is known for its involvement in eye movement generation and attentional control (Hikosaka et al., 2000). Striatal DA has been implicated in reward processing (Berridge and Robinson, 1998; Haber, 2011; Deserno et al., 2016; Katthagen et al., 2020), voluntary motor behavior (Albin et al., 1989; Joshua et al., 2009; Klaus et al., 2019), learning and motivation (Berridge and Robinson, 1998; Waelti et al., 2001; Graybiel, 2008) as well as in the involuntary attention orienting toward reward-related cues (Anderson et al., 2016). For example, Cameron et al. (2018) orally administered tolcapone capsules (Catechyl-O-Methyltransferase 
(COMT) inhibitor) and bromocriptine capsules (D2 agonist) to human participants performing a visual attention task, that required switching between pro- and anti-saccade responses. Greater prefrontal DA tone led to a reduced performance in the visual task. The authors concluded that DA might facilitate inhibitory control, which could have resulted in an excessive focusing of attention and might have been sub-optimal for the task at hand.

Dopaminergic activity has also been associated with several attention networks: the dorsal attention network (DAN, externally controlled attention; Corbetta and Shulman, 2002), the default mode network (DMN, internal cognitive processes; Raichle et al., 2001; Raichle, 2015) and the fronto-parietal control network, which is assumed to mediate the allocation of attentional resources between the two other networks (FCPN; Spreng et al., 2010). It was found that blocking DA reuptake increases DAN activation during visual attention tasks (Müller et al., 2005; Tomasi et al., 2011) and alters DMN activation (Tomasi et al., 2011). Additionally, Dang et al. (2012) demonstrated that DA influenced the interaction between DAN, DMN and FPCN.

Further evidence for the role of DA in attention comes from studies focusing on inattention. As it was shown, inattention can be attributed to disruptions of DA activity. Gorgoraptis et al. (2012), for example, demonstrated that a dopaminergic agonist (transdermal rotigotine) had beneficial effects on visual search and selective attention in patients with hemispatial neglect following stroke. Some stimulant medications used in the treatment of inattention, like methylphenidate and amphetamine, enhance dopaminergic activity by targeting DA transporters (DAT; Seeman and Madras, 1998; Wang et al., 2013; Robison et al., 2017). In line with this mode of action, Tomasi et al. (2009) found that lower DAT (higher DA activity) facilitated visual attention by modulating brain deactivations in default mode regions, such as the precuneus.

On a side note, DA also seems to have a direct influence on retinal vision by tuning visual processing through cellular and circuit-level mechanisms within the retina (Witkovsky, 2004; Roy and Field, 2019). For instance, DA signaling has been shown to impact spatial and temporal receptive fields of retinal neurons (Chaffiol et al., 2017; Mazade et al., 2019).

\section{DA Effects on Bottom-Up and Top-Down Visual Attention}

Dopaminergic activity in the PFC is important for a variety of cognitive processes, such as working memory, motivation and action planning (Ayano, 2016). At the same time, the PFC is assumed to be essential for the top-down regulation of attention through long-range projections upon visual areas (Baluch and Itti, 2011; Noudoost and Moore, 2011; Paneri and Gregoriou, 2017). Recently, it was demonstrated that DA modulation in the PFC operates through phasic activation of dopaminergic neurons that modify PFC activity and gamma oscillations (Lohani et al., 2019). Some evidence for the role of DA in top-down attentional control comes from Prinzmetal et al. (2010). The authors investigated the effect of D2 receptor agonist bromocriptine in a visual cueing task targeting spatial attention. Bromocriptine enhanced the effect of spatial cueing for long Stimulus-Onset-Asynchrony (SOA), but not for short SOA trials. Thus, dopaminergic modulation seems to affect voluntary but not involuntary spatial attention. One region of the PFC, the frontal eye field (FEF), is believed to be particularly important in attentional control and seems to be modulated by dopaminergic activity (Noudoost and Moore, 2011, 2012; Chandler et al., 2014; Mueller et al., 2020). Noudoost and Moore (2011) examined the effect of D1 receptor blockade on FEF activity in macaques. They used microinjections to applicate D1 receptor antagonists (SCH23390) into sites within the FEFs while simultaneously recording activity from matching sites in V4. The authors found that manipulating FEF activity increased target selection, but also magnitude, selectivity and reliability of V4 responses. These effects were concluded to be similar to those of covert attention in absence of a behavioral task (Noudoost and Moore, 2011). In another experiment, the authors used a D2 receptor agonist (quinpirole), which also led to an increase in target selection. However, only D1 receptor manipulation affected V4 responses (Chudasama and Robbins, 2004; Noudoost and Moore, 2011; Yousif et al., 2016). To explain these discrepant results, it was suggested that D1 receptors are more involved in generating top-down attention signals than D2 receptors. Thiele and Bellgrove (2018) concluded that this functional dissociation might be explained by the differing amounts of D1 and D2 receptors in supragranular and infragranular layers of the FEF (with D1 receptors being expressed in both layers and D2 receptors being expressed only in infragranular layers; Lidow et al., 1991). While dopaminergic input derived from the substantia nigra preferentially terminates in supragranular layers and could be more involved in increasing attentional feedback signals, dopaminergic input derived from the ventral tegmental area preferentially terminates in infragranular layers and could be more involved in reward and error processing.

However, the FEFs have not only been associated with topdown control but also with bottom-up processing. Based on visual search experiments in non-human primates it is assumed that the FEFs might contain the neural correlate of a salience map or be part of a distributed network representing visual salience (Thompson and Bichot, 2005). As such, the FEFs would process top-down as well as bottom-up factors (Thompson and Bichot, 2005; Katsuki and Constantinidis, 2012, 2014; Joiner et al., 2017). In line with this assumption, there is some evidence of dopaminergic involvement in bottom-up visual attention. Lundwall et al. (2012), for example, demonstrated that exogenous orienting was associated with dopaminergic markers on COMT and DAT1. Anderson et al. (2016) explored the contribution of DA to value-based attention in a positron-emission-tomography (PET) study. They found that DA signaling in the striatum was linked to involuntary attention orienting-particularly to the exogenous attraction of attention by reward cues. Enhanced levels of DA were associated with reward-related attentional capture, while suppression of DA release was associated with the ability to ignore reward-related stimuli. Contrary to these results, Rokem et al. (2012) reported no effect of DAT1 genotype or D2 receptor agonist bromocriptine on involuntary attention. 


\section{Summary}

Dopaminergic neurons contribute to a variety of cognitive functions and disruptions of dopaminergic activity are associated with several psychiatric and neurodegenerative dieseases. With regard to visual attention, DA seems to exert its influence primarily through dopaminergic activity in the PFC/FEF and related brain networks (DAN). These regions have been shown to modulate attention via top-down projections upon the visual cortex (Noudoost and Moore, 2011). A recurring finding is that the effect of DA is dependent on receptor type and localization. D1 and D2 receptors have been found to be differentially expressed within different layers of the primate frontal cortex and while DA acts on both receptor types, its main actions related to top-down attention occur at the D1 receptor, which is found in superficial and deeper layers of the PFC (Lidow et al., 1991; Arnsten and Pliszka, 2011; Soltani et al., 2013; Mueller et al., 2020).

\section{Noradrenaline General}

The Locus Coeruleus (LC) is known as the main source of noradrenaline (NA) in the brain. In this region, NA is synthesized directly from DA by the dopamine- $\beta$-hydroxylase (Loizou, 1969; Bari et al., 2020). There exist several subtypes of adrenergic receptors, most often classified in $\alpha$ and $\beta$ families, which can again be subdivided into $\alpha_{1}$ and $\alpha_{2}$ or $\beta_{1}, \beta_{2}$ and $\beta_{3}$ receptor categories (Strosberg, 1993; Xing et al., 2016). NA has the highest affinity for $\alpha_{2}$-receptors (Arnsten, 2000) and the $\alpha_{2 A}$ subtype is most prevalent within the PFC. NA seems to be broadly released in the brain (Levitt and Moore, 1978), in tonic and phasic firing modes. These two modes have been associated with arousal and wakefulness on the one hand and novelty and behaviorally driven exploration on the other hand (Vankov et al., 1995; Berridge and Waterhouse, 2003; O'Donnell et al., 2012; Aston-Jones and Waterhouse, 2016; Thiele and Bellgrove, 2018).

\section{Effects of NA on Top-Down and Bottom-Up Visual Attention}

DA and NA show overlapping effects on learning, brain state and reward processing (Ranjbar-Slamloo and Fazlali, 2020). They are also implicated in modulating attention (Clark et al., 1989; Ward and Brown, 1996; Coull et al., 2001; De Martino et al., 2008; Borodovitsyna et al., 2017). In addition, both catecholamines are assumed to synergistically modulate PFC functioning (Xing et al., 2016), which might imply that they are both involved in top-down processing of attention (Arnsten and Pliszka, 2011). However, Shalev et al. (2019) demonstrated that the effects of DA and NA on visual attention can be dissociated. They found that attentional selection was associated with the COMT genotype, while sustained attention was linked to the dopamine-beta-hydroxylase (DBH) genotype. NA also shares similarities with ACh concerning its role in attentional processing (Thiele and Bellgrove, 2018). For example, using a Bayesian statistical framework, it was suggested that NA and ACh control selective attention, flexible information processing and learning by forming an interactive, partly synergistic, partly antagonistic relationship in the representation of expected (ACh) and unexpected (NA) uncertainty (Yu and Dayan, 2005).

In general, noradrenergic activity has been found to influence attentional orienting (Coull et al., 2001; Sara and Bouret, 2012), disengagement of attention (Clark et al., 1989) and attentional shifting (Snyder et al., 2012). Specifically, NA seems to be involved in salience detection (Foote et al., 1980; Aston-Jones and Bloom, 1981; Servan-Schreiber et al., 1990; Berridge and Waterhouse, 2003; De Martino et al., 2008; Markovic et al., 2014; Mather et al., 2016; Gelbard-Sagiv et al., 2018). In addition, noradrenergic signaling is supposed to enhance the ability to discriminate between relevant and irrelevant information (Aston-Jones and Cohen, 2005) and thus bias attentional tuning (Ehlers and Todd, 2017). For example, Gelbard-Sagiv et al. (2018) manipulated noradrenergic activity using clonidine (an $\alpha 2$ agonist, should reduce NA activity and task performance) and reboxetine (selective NA reuptake inhibitor, should increase NA signaling) and examined their effect on visual perception, EEG and fMRI responses. They found that visual detection and stimulus discrimination were affected by NA manipulations as expected, while decision bias and sustained attention were not. Moreover, they found that the reduction of NA signaling affected ERP components and brain regions associated with visual awareness. These results indicate that NA influences primarily the later stages of perceptual processing and not attentional function per se (Gelbard-Sagiv et al., 2018; see also Nieuwenhuis et al., 2007). However, in the study by GelbardSagiv et al. (2018) reboxetine did show a trend toward an increased performance in the sustained attention task. If so, the authors conclued, bottom-up attentional processes might be more in line with noradrenergic influences on sensory processing. Underlining the role of NA in stimulus-associated processing, several studies found that NA as well as ACh suppressed topdown information in favor of bottom-up sensory information (Hasselmo et al., 1996; Kimura et al., 1999; Kobayashi et al., 2000; Yu and Dayan, 2005). Contrary to this, Dockree et al. (2017) demonstrated that methylphenidate, a mixed DA and NA reuptake inhibitor, improved sustained attention by acting on top-down attentional control with no effect on stimulus-driven, sensory processes.

Interestingly, as with dopaminergic D1 receptor stimulation, it was demonstrated that insufficient as well as extreme catecholaminergic activity can have negative effects on attention performance (Berridge and Waterhouse, 2003; Aston-Jones and Cohen, 2005; Arnsten and Pliszka, 2011; Shalev et al., 2019). While moderate levels of NA have been shown to improve PFC function by acting on $\alpha_{2}$ receptors, high levels of NA might decrease PFC function through $\alpha_{1}$ or $\beta$ receptors (Arnsten, 2000; Lapiz and Morilak, 2006; Arnsten and Pliszka, 2011). The opposing effects of high and low NA concentration on distinct adrenoceptors with different affinities could also be the reason for the discrepant results concerning bottom-up and top-down attentional control. This conflict might be resolved by assuming that $\alpha_{2}$ receptors in the PFC regulate top-down attention (Coull et al., 2001; Robbins and Arnsten, 2009; Mather et al., 2016) and $\alpha_{1}$ receptors in the sensory cortex modulate bottom-up processes (Thiele and Bellgrove, 2018). 


\section{Summary}

There is evidence that NA primarily influences visual perception (Gelbard-Sagiv et al., 2018) and salience detection (Markovic et al., 2014; Mather et al., 2016). However, the role of moderate noradrenergic levels in enhancing PFC functions seem to imply an additional effect on top-down attention, working memory, decision-making and emotional regulation (Berridge and Waterhouse, 2003; Arnsten, 2009; Ehlers and Todd, 2017). The heterogeneous role of NA in biasing attentional processes could be explained by taking into account the different localizations, affinities and effects of adrenergic receptors. While top-down effects might depend on moderate levels of NA enhancing PFC function, acting on $\alpha 2$ receptors; bottom-up effects might be associated with higher levels of NA, decreasing PFC function by acting on $\alpha 1$ or $\beta$ receptors (Arnsten and Pliszka, 2011; Thiele and Bellgrove, 2018).

\section{Serotonin General}

Serotonin (5-hydroxytryptamine, 5-HT) is synthesized from L-tryptophan and released by serotonergic neurons in the Raphe nuclei of the brainstem (Mohammad-Zadeh et al., 2008; Walker and Tadi, 2020). There exist at least fourteen 5-HT receptor subtypes (Hoyer et al., 1994), which regulate distinct physiological processes (Hoyer and Martin, 1997; Stiedl et al., 2015). The most prevalent and extensively researched receptor types are the 5-HT1A and the 5-HT2A receptors (Carhart-Harris and Nutt, 2017). 5HT is mostly found outside the central nervous system, where it regulates biological processes associated with cardiovascular, pulmonary or gastrointestinal functions (Berger et al., 2009). However, 5-HT is also important within the central nervous system and seems to regulate almost all brain functions. Accordingly, it has been implicated in the pathogenesis of several psychiatric and neurological disorders (Berger et al., 2009).

\section{Effects of 5-HT Modulation on Top-Down and Bottom-Up Visual Attention}

5-HT receptors, especially 5-HT2A receptors, are highly expressed in the PFC (Puig and Gulledge, 2011). Consequently, 5-HT has been implicated in executive functions, emotion and motivation, learning and memory (Meneses and Liy-Salmeron, 2012). While serotonin activity seems to play an especially important role in prepotent response inhibition and impulsivity with less impact on attentional processing (Robbins, 2002; Brown et al., 2012; Worbe et al., 2014), it also seems to have some influence on attentional processing (Carter et al., 2005; Scholes et al., 2007; Wingen et al., 2008; Enge et al., 2014; Li et al., 2018). Carter et al. (2005) found that treatment with psyilocybin, a mixed 5-HT1A and 5-HT2A agonist, impaired the ability to suppress distractors and subsequently reduced attentional performance. Since a pretreatment with the 5-HT2A agonist ketanserin did not modulate the effect of psilocybin, the authors assumed that attentional processes primarily rely on 5HT1A receptors. Even so, genetical manipulation of neurons expressing 5-HT2C receptors in the hippocampus exclusively modulated performance in a visual attention task (Li et al., 2018). Application of a selective serotonin reuptake inhibitor (escitalopram) led to a reduced activation in areas concerned with sustained attention (frontal regions, the thalamus and nucleus caudate, measured by fMRI; Wingen et al., 2008). Behaviorally, participants reported decreased alertness, but there was no effect of escitalopram on the performance of a sustained attention task (Mackworth Clock Test). Concerning attentional selection, an investigation of genetic variations in key regulators of serotonergic and noradrenergic systems comes to the conclusion that 5-HT is involved in top-down attentional control (Enge et al., 2014). In addition, dopamine and 5HT depletion (acute tryptophan or tyrosine/phenylalanin depletion) decreased performance in a Stroop interference task, indicating an increase in attentional control (Scholes et al., 2007).

\section{Summary}

5-HT has diverse functions in brain and body. Serotonergic signaling is also indicated in attention (Carter et al., 2005; Wingen et al., 2008), mainly in the processing of top-down attentional control (Scholes et al., 2007; Enge et al., 2011, 2014). However, information on how 5-HT influences voluntary and involuntary attentional mechanisms is limited and might demand further investigation.

\section{Oxytocin General}

Oxytocin is a nine amino acid neuropeptide, acting as a hormone and a neurotransmitter. It is synthesized in several nuclei of the hypothalamus (Mirtre et al., 2018). In the periphery, oxytocin has long been associated with lactation, osmoregulation and the regulation of energy balance (Ho and Blevins, 2013). However, oxytocin also plays an important role within the central nervous system, where it is implicated in social approach and maternal care behaviors, as well as in emotion processing (Yuan and Hou, 2015). Accordingly, oxytocin receptors appear to be more densely expressed in areas associated with emotion and social behaviors (e.g., amygdala, nucleus accumbens; Huber et al., 2005; Lee et al., 2009; Mirtre et al., 2018).

\section{Effects of Oxytocin Modulation on Top-Down and Bottom-Up Visual Attention}

A great amount of research has described oxytocin as an important neuromodulator of social and emotional processing (Yuan and Hou, 2015). In addition, it has been associated with cognitive functions such as the processing of sensory stimuli, social recognition, social memory and fear regulation (Ross and Young, 2009; Choe et al., 2015; Oettl et al., 2016; Jones et al., 2017; Grinevich and Stoop, 2018). Furthermore, oxytocin was found to influence selective attention when social stimuli were involved. Therefore, we have included it in this review.

For example, oxytocin modulated involuntary attention orienting to social stimuli (Puglia et al., 2018) and attentional allocation to social cues by influencing the interactions between brain networks associated with internal or external attentional control (Xin et al., 2018). These results are in line with other studies showing that oxytocin regulates visual attention and eye movements to external social stimuli (Domes et al., 2012, 2013; Clark-Elford et al., 2014). It was also hypothesized that oxytocin 
plays a prominent role in alerntness. Stoop (2012) proposed that vasopressin-a substance closely related to oxytocin-increases alert for external stimuli, while oxytocin decreases alert by modulating amygdala activity. Several studies indeed found a normalization of amygdala responses and attentional bias toward threat related cues after oxytocin application (Labuschagne et al., 2012; Clark-Elford et al., 2014). On the contrary, other studies have found an increase in attention toward emotional stimuli under oxytocin (Domes et al., 2013; Tollenaar et al., 2013; ClarkElford et al., 2014; Xin et al., 2018). These discrepant results might be associated with natural variability in the DNA methylation of the oxytocin receptor gene, which has been linked to social attention capabilities (Puglia et al., 2018).

\section{Summary}

While ACh and DA are already established neuromodulators of attentional control, research has only recently begun to target the attentional effects of oxytocin. While the exact nature of these effects and their neural basis are not yet completely clear, it seems that oxytocin modulates visual selective attention to external social events (Domes et al., 2012, 2013; Clark-Elford et al., 2014).

\section{Glutamate \\ General}

Although the neurotransmitters glutamate and gammaaminobutyric acid (GABA) cannot be counted among brain neuromodulators, they fulfill important roles in brain functioning and cognitive processing. Together, these substances modulate the inhibitory-excitatory balance, which is crucial for cortical excitability and thus for normal brain functioning (Hampe et al., 2018). While the effects of GABA are mainly inhibitory, glutamate is the most important excitatory neurotransmitter in the brain. It exerts its influence on $G$ protein-coupled metabotropic and ionotropic receptors that can be diveded into several subtypes (Vyklicky et al., 2014; Uno and Coyle, 2019). From these receptors, the ionotropic NMDA (N-Methyl-D-Aspartate) receptor type has been most extensively studied and is known to have important functions in synaptic transmission, plasticity and cogition (Collingridge et al., 2013; Kocsis et al., 2013; Vyklicky et al., 2014; Dauvermann et al., 2017; Valtcheva and Venance, 2019).

\section{Effects of Glutamate on Top-Down and Bottom-Up Visual Attention}

Several studies have found that subanesthetic doses of the NMDA receptor antagonist ketamine induce psychoses-like symptoms in healthy volunteers (Krystal et al., 1994; Malhotra et al., 1996). Ketamine influences memory (Malhotra et al., 1996; Morgan and Curran, 2006) and modulates attentional processes (Oranje et al., 2000; Watson et al., 2009; GunduzBruce et al., 2012; Fuchs et al., 2015; von Düring et al., 2019; but see Morgan et al., 2004; van Wageningen et al., 2010). For example, Fuchs et al. (2015) investigated the influence of ketamine on top-down attentional control using a visual cueing paradigm. They found ketamine-induced impairments in voluntary attentional shifts to peripheral cues, but no drug effects on involuntary attentional cueing. Studies that examined the effect of ketamine on EEG data during visual or auditory attentional tasks generally demonstrate altered ERP amplitudes (P3: Oranje et al., 2000; Watson et al., 2009; Gunduz-Bruce et al., 2012; N2: Watson et al., 2009; N1: Oranje et al., 2000; MMN: Gunduz-Bruce et al., 2012). One study investigated the effect of low doses of ketamine on performance in a visual oddball task during simultaneous measuring of EEG, fMRI and electrodermal activity (Musso et al., 2011). The authors found decreased P3 amplitudes and BOLD responses under ketamine in regions commonly associated with selective attention. Thus, NMDA blockade affects early attentional processes as well as later voluntary control mechanisms (Watson et al., 2009). Schwertner et al. (2018) assumed that ketamine modulates EEG components by influencing stimulus discriminability (but see Rosburg and Schmidt (2018) for a different interpretation). This is in line with other research demonstrating that ketamine impairs the ability to both effectively gate the processing of sensory stimuli and process salient stimuli (Krystal et al., 1999; Umbricht et al., 2002). Thus, NMDA receptor functioning might play an important role in detecting changes in the environment, which is assumed to be central for the ability to orient toward salient novel stimuli. In this context, it is also regularly reported that ketamine has a strong influence on gamma-band oscillations (Thiebes et al., 2018; Curic et al., 2019), which seem to have an important role in bottomup processing, perception and selective attention (Richter et al., 2017; Thiebes et al., 2018; Riddle et al., 2019).

\section{Summary}

The role of neurotransmitters in attention processing is less extensively studied than the roles of neuromodulators. However, there is increasing evidence that manipulation of the NMDA receptor with ketamine might have an effect on top-down (van Wageningen et al., 2010; Fuchs et al., 2015) and bottom-up attentional processing (Gunduz-Bruce et al., 2012). Most of this evidence comes from EEG studies demonstrating ketamine effects on several attention-related EEG components. In contrast to previous interpretations (Schwertner et al., 2018), Rosburg and Schmidt (2018) suggested that the reduced P3 amplitudes found after ketamine treatment are better explained by working memory impairments than by a drug-related increase in task difficulty due to alterations of perceived stimulus salience. On the other hand, the influence of ketamine on high frequency oscillations does suggest a connection between glutamate, bottom-up attentional processing and selective attention (Thiebes et al., 2018).

\section{GABA}

\section{General}

While glutamate is the brain's main excitatory neurotransmitter, the role of GABA in the mature brain appears to be mostly inhibitory. As with $\mathrm{ACh}$, there are two main types of GABA receptors: an ionotropic $\mathrm{GABA}-\mathrm{A}$ receptor and a metabotropic GABA-B receptor (Wu et al., 2016). While $20-30 \%$ of cortical neurons are GABAergic interneurons (Schmidt-Wilcke et al., 2018), the effects of GABA are not limited to inhibitory synaptic modulation. It is assumed to be involved in numerous cognitive functions (Schmidt-Wilcke et al., 2018; Kim et al., 2019). 
For example, GABA was found to influence working memory (Duncan et al., 2014; Yoon et al., 2016), impulsivity (Boy et al., 2011; Yoon et al., 2016), action selection (Steenbergen et al., 2015) and motor function (Stinear and Byblow, 2003; Zoghi et al., 2003; Duncan et al., 2014). On the other hand, GABA dysfunctions have been associated with several brain diseases (Schür et al., 2016; Kim Y.S. et al., 2017) and psychiatric disorders, such as schizophrenia (de Jonge et al., 2017), OCD (Li et al., 2019) or attention-deficit-hyperactiviy-disorder (ADHD; Edden et al., 2012).

\section{Effects of GABA on Top-Down and Bottom-Up Visual Attention}

Animal studies have found GABA to be involved in the regulation of attentional resources (Katzner et al., 2011; Paine et al., 2011; McGarrity et al., 2017) and to shape performance in visuo-spatial attention tasks (Petersen et al., 1987; Pezze et al., 2014). In humans, GABA seems to improve attentional selectivity in the visual cortex (van Loon et al., 2013; Sandberg et al., 2014), either by inhibiting irrelevant sensory information or by increasing the specifity of neural representation (Sandberg et al., 2014; Frangou et al., 2019). There is some evidence indicating that GABA might affect temporal aspects of attentional control more than spatial aspects (Kihara et al., 2016; Leonte et al., 2018). Furthermore, GABA can influence attentional processing through modulating cholinergic inputs. In rats, the infusion of positive and negative GABA modulators into the basal forebrain augments and decreases (respectively) the excitability of cholinergic projections, affecting performance in sustained attention tasks in both directions (Sarter, 1994; Moore et al., 1995; Sarter et al., 2001). This is in line with recent assumptions of GABA/ACh cotransmission (Saunders et al., 2015; Ma et al., 2018). In the study of Sandberg et al. (2014) participants with high GABA concentration in occipital areas (quantified by MR spectroscopy) reported to be better able to ignore irrelevant information. The authors speculated that a high GABA level does not automatically lead to more inhibition of bottom-up signals but that this GABAergic suppression can be influenced by top-down signals to match relevant behavioral goals. As such, high GABA levels would indicate the "potential strength of suppression between competing visual stimuli" (Sandberg et al., 2014).

\section{Summary}

In contrast to some neuromodulators, the evidence for GABA involvement in attentional processing seems to be quite solid. GABA was shown to shape visual attention by suppression of bottom-up signals and improving attentional selectivity in early visual areas (van Loon et al., 2013; Sandberg et al., 2014). These effects might be influenced by top-down signals (Sandberg et al., 2014) and implemented at least partly through modulation of cholinergic inputs (Saunders et al., 2015).

\section{CONCLUSION}

In this review, we have discussed the importance and relative contributions of different neuromodulators to voluntary and involuntary visual attention. However, while the central roles of cholinergic, dopaminergic and noradrenergic systems in selective attention are widely accepted, there is less evidence concerning other neuromodulators, like serotonin or oxytocin. The same can be said about top-down and bottom-up attention. Whereas top-down processes are already subject to comprehensive investigations, the neuromodulatory mechanisms underlying bottom-up attention are less clear, as well as the neurochemical processes supporting a possible interaction of bottom-up and top-down systems. In general, dopamine and serotonin seem to be more closely associated with top-down attentional mechanisms, whereas acetylcholine, noradrenaline and oxytocin might also subserve specific roles in visual detection, salience processing and exogenous attentional orienting. The situation is complicated by the circumstance that the effects of neuromodulators in attentional processing seem to change depending on brain region, receptor subtype, level, task or release mode. For example, top-down and bottomup effects might be driven by an interplay of cholinergic activity at muscarinic and nicotinic receptor types, with nACh receptors being more involved in modulating bottom-up attention and muscarinic receptor types being more involved in top-down attention. At the same time, the effects of most neuromodulators seem to vary across different brain regions. ACh might influence visual processing in primary visual cortex (via $\mathrm{mACh}$ receptors) and attention in higher cortical areas (via nACh receptors). Furthermore, the effect of NA was shown to increase or decrease PFC function depending on the different affinities of its adrenergic receptors for moderate or high neuromodulator levels. In addition, it was found that several neuromodulators show tonic and phasic firing modes, which might also influence their effects on attentional processing. Since bottom-up and top-down attention appear to be closely connected and neuromodulators have been shown to directly and indirectly interact (Avery and Krichmar, 2017), it is imaginable that some or even all of these processes work synergistically to shape human selective attention.

\section{FUTURE DIRECTIONS}

Research about neuromodulatory effects on visual attention are complicated by the fact that attentional processes are hard to discriminate from working memory. Attention and working memory are closely intertwined and appear to be supported by overlapping mechanisms and brain regions (LaBar et al., 1999; Awh et al., 2006; Theeuwes et al., 2009; Gazzaley and Nobre, 2012). Therefore, it is not suprising that some neuromodulators have been shown to influence both processes (Arnsten and Goldman-Rakic, 1990; Sawaguchi and GoldmanRakic, 1994; Gamo et al., 2010). Thus, future studies should be mindful of this interaction and try to include paradigms which are able to seperate working memory and attentional processes. Furthermore, including neuromodulators that are not yet extensively studied, such as oxytocin, might help gaining valuable insights about specific subcomponents of visual attention (in this case: social attention) and putting together a 
more complete picture of how visual attention is represented, modulated and expressed in the human brain. Another issue for future research might be the dissociation of attentional processes. It is still not sufficiently clear how different neuromodulators, their specific properties (e.g., receptor affinities, firing mode) or their neuronal interactions influence bottom-up and topdown control or the interplay of both processes. On top of that, recent studies have reported that the dichotomy of topdown and bottom-up attention seems to be obsolete and should be replaced by a more comprehensive model, that includes other factors such as reward and past selection history (Awh et al., 2012). For example, Hickey et al. (2010) showed that reward automatically triggered a selection bias toward a rewardassociated feature, even when attending to that feature was opposed to the goals of the participant. Thus, there appear to be other influences on attentional selection than stimulus salience or voluntary intentions. In spite of these findings, there are still many open questions about the way reward affects the coordination of visual salience and voluntary attentional control (Feldmann-Wüstefeld et al., 2016), as well as concerning the underlying neurophysiological and neurobiological mechanisms. Since dopamine was shown to play a prominent role in reward processing, as well as in voluntary attention, this interaction might be an interesting starting point for future studies. Another promising area seems to be the investigation of brain oscillations. Several neuromodulators were found to influence brain oscillations during attentional processing. For example, ACh was shown to modulate gamma synchrony in rats (Howe et al., 2017) or alpha and beta oscillations in humans (Bauer et al., 2012). Additionally, DA could modulate PFC activity through phasic activiation of dopaminergic neurons that modify PFC activity and gamma oscillations (Lohani et al., 2019). This is important because neuronal communication is not just determined by anatomical connectivity and activitydependent changes to the anatomical structure of the connection, but also by neuronal synchronization. Dynamic changes in synchronization might even be a core feature of cognition (Fries, 2015). Consequently, high-frequency gamma oscillations

\section{REFERENCES}

Albin, R. L., Young, A. B., and Penney, J. B. (1989). The functional anatomy of basal ganglia disorders. Trends Neurosci. 12, 366-375. doi: 10.1016/0166-2236(89) 90074-x

Alvarez-Jimenez, R., Hart, E., Prins, S., de Kam, M., Gerven, J., Cohen, A., et al. (2018). Reversal of mecamylamine-induced effects in healthy subjects by nicotine receptor agonists: cognitive and (electro) physiological responses. Br. J. Clin. Pharmacol. 84, 888-899. doi: 10.1111/bcp. 13507

Anderson, B. A., Kuwabara, H., Wong, D. F., Gean, E. G., Rahmim, A., Brašić, J. R., et al. (2016). The role of dopamine in value-based attentional orienting. Curr. Biol. 26, 550-555. doi: 10.1016/j.cub.2015.12.062

Arnsten, A. F. (2000). Stress impairs prefrontal cortical function in rats and monkeys: role of dopamine D1 and norepinephrine alpha-1 receptor mechanisms. Prog. Brain Res. 126, 183-192. doi: 10.1016/S0079-6123(00) 26014-7

Arnsten, A. F. (2009). Stress signalling pathways that impair prefrontal cortex structure and function. Nat. Rev. Neurosci. 10, 410-422. doi: 10.1038/nrn2648. Stress
(30-100 Hz) were found to accompany various cognitive and psychological processes (Uhlhaas et al., 2011), coordinating activity within local circuits and between distant brain regions (Fries, 2015). It is assumed that oscillations in different frequency bands might subserve specific roles in selective attention. For example, gamma band oscillations seem to primarily carry out influences mediated by bottom-up projections, whereas influences mediated by top-down projections are carried out by alpha-beta band synchronization (Bastos et al., 2012). Interestingly, these top-down beta band influences are assumed to directly modulate bottom-up gamma band via cross-frequency interaction (Richter et al., 2017). In accordance with the development of new non-invasive stimulation methods (TMS, tDCS), that are specifically designed to target neural oscillations and the associated cognitive processes, the investigation of brain oscillations and their task-specific frequency profiles in connection with neurochemical modulation of different attentional processes (top-down, bottom-up, reward) seems to be a promising field for future research.

\section{AUTHOR CONTRIBUTIONS}

The order of authorship was a joint decision of the co-authors. Each author has participated sufficiently in the work to take public responsibility for the content. Authorship credit was based on substantial contribution to conception and design, execution, or analysis and interpretation of data. Both authors were involved in drafting the article or revising it critically for important intellectual content, read and approved the final version of the manuscript, and qualified for authorship.

\section{FUNDING}

This work was funded by the Deutsche Forschungsgemeinschaft (DFG, German Research Foundation)_project number 222641018-SFB/TRR 135 TP B7.

Arnsten, A. F., and Goldman-Rakic, P. S. (1990). Stress impairs prefrontal cortex cognitive function in monkeys: role of dopamine. Soc. Neurosci. Abstr. $16,164$.

Arnsten, A. F., and Pliszka, S. R. (2011). Catecholamine influences on prefrontal cortical function: relevance to treatment of attention deficit hyperactivity disorder and related disorders. Pharmacol. Biochem. Behav. 99, 211-216.

Aston-Jones, G., and Bloom, F. E. (1981). Norepinephrine-containing locus coeruleus neurons in behaving rats exhibit pronounced responses to nonnoxious environmental stimuli. J. Neurosci. 1, 887-900.

Aston-Jones, G., and Cohen, J. D. (2005). An integrative theory of locus coeruleus-norepinephrine function: adaptive gain and optimal performance. Annu. Rev. Neurosci. 28, 403-450. doi: 10.1146/annurev.neuro.28.061604. 135709

Aston-Jones, G., and Waterhouse, B. D. (2016). Locus coeruleus: from global projection system to adaptive regulation of behavior. Brain Res. 1645, 75-78.

Avery, M. C., and Krichmar, J. L. (2017). Neuromodulatory systems and their interactions: a review of models, theories, and experiments. Front. Neural Circ. 11:108. doi: 10.3389/fncir.2017.00108 
Awh, E., Belepolsky, A. V., Theeuwes, J., and Belopolsky, A. V. (2012). Top-down versus bottom-up attentional control: a failed theoretical Dichotomy. Trends Cogn. Sci. 16, 437-443. doi: 10.1016/j.tics.2012.06.010

Awh, E., Vogel, E. K., and Oh, S. H. (2006). Interactions between attention and working memory. Neuroscience 139, 201-208. doi: 10.1016/j.neuroscience.2005. 08.023

Ayano, G. (2016). Dopamine: receptors, functions, synthesis, pathways, locations and mental disorders: review of literatures. J. Ment. Disord. Treat. 2, 2-5. doi: 10.4172/2471-271x.1000120

Ballinger, E., Ananth, M., Talmage, D. A., and Role, L. W. (2016). Basal forebrain cholinergic circuits and signaling in cognition and cognitive decline. Neuron 91 , 1199-1218.

Baluch, F., and Itti, L. (2011). Mechanisms of top-down attention. Trends Neurosci. 34, 210-224. doi: 10.1016/j.tins.2011.02.003

Bari, B. A., Chokshi, V., and Schmidt, K. (2020). Locus coeruleus-norepinephrine: basic functions and insights into Parkinson's disease. Neural Regen. Res. 15, 1006-1013. doi: 10.4103/1673-5374.270297

Bartus, R. T., Dean, R. L., Beer, B., and Lippa, A. S. (1982). The cholinergic hypothesis of geriatric memory dysfunction. Science 217, 408-414. doi: 10.1126/ science.7046051

Bastos, A. M., Usrey, W. M., Adams, R. A., Mangun, G. R., Fries, P., and Friston, K. J. (2012). Canonical microcircuits for predictive coding. Neuron 76, 695-711. doi: 10.1016/j.neuron.2012.10.038

Bauer, M., Kluge, C., Bach, D., Bradbury, D., Heinze, H. J., Dolan, R. J., et al. (2012). Cholinergic enhancement of visual attention and neural oscillations in the human brain. Curr. Biol. 22, 397-402. doi: 10.1016/j.cub.2012.01.022

Bentley, P., Husain, M., and Dolan, R. J. (2004). Effects of cholinergic enhancement on visual stimulation, spatial attention, and spatial working memory. Neuron 41, 969-982. doi: 10.1016/S0896-6273(04)00145-X

Berger, M., Gray, J. A., and Roth, B. L. (2009). The expanded biology of serotonin. Annu. Rev. Med. 60, 355-366. doi: 10.1146/annurev.med.60.042307.110802

Berridge, C. W., and Waterhouse, B. D. (2003). The locus coeruleus-noradrenergic system: modulation of behavioral state and state-dependent cognitive processes. Brain Res. Rev. 42, 33-84. doi: 10.1016/S0165-0173(03)00143-7

Berridge, K. C., and Robinson, T. E. (1998). What is the role of dopamine in reward: hedonic impact, reward learning, or incentive salience? Brain Res. Rev. 28, 309-369. doi: 10.1016/S0165-0173(98)00019-8

Bisley, J. W., and Goldberg, M. E. (2010). Attention, intention, and priority in the parietal lobe. Annu. Rev. Neurosci. 33, 1-21. doi: 10.1146/annurev-neuro060909-152823

Borodovitsyna, O., Flamini, M., and Chandler, D. (2017). Noradrenergic modulation of cognition in health and disease. Neural Plast. 2017, 57-59. doi: 10.1155/2017/6031478

Bosman, C. A., Schoffelen, J. M., Brunet, N., Oostenveld, R., Bastos, A. M., Womelsdorf, T., et al. (2012). Attentional stimulus selection through selective synchronization between monkey visual areas. Neuron 75, 875-888. doi: 10 . 1016/j.neuron.2012.06.037

Boy, F., Evans, C. J., Edden, R. A., Lawrence, A. D., Singh, K. D., Husain, M., et al. (2011). Dorsolateral prefrontal $\gamma$-aminobutyric acid in men predicts individual differences in rash impulsivity. Biol. Psychiatry 70, 866-872. doi: 10.1016/j. biopsych.2011.05.030

Briand, L. A., Gritton, H., Howe, W. M., Young, D. A., and Sarter, M. (2007). Modulators in concert for cognition: modulator interactions in the prefrontal cortex. Prog. Neurobiol. 83, 69-91. doi: 10.1016/j.biopsych.2011.05.030

Brown, H. D., Amodeo, D. A., Sweeney, J. A., and Ragozzino, M. E. (2012). The selective serotonin reuptake inhibitor, escitalopram, enhances inhibition of prepotent responding and spatial reversal learning. J. Psychopharmacol. 26, 1443-1455.

Cameron, I. G. M., Wallace, D. L., Al-Zughoul, A., Kayser, A. S., and D'Esposito, M. (2018). Effects of tolcapone and bromocriptine on cognitive stability and flexibility. Psychopharmacology 235, 1295-1305. doi: 10.1007/s00213-0184845- 4

Carcea, I., and Froemke, R. C. (2013). Cortical plasticity, excitatory-inhibitory balance, and sensory perception. Prog. Brain Res. 207, 65-90.

Carhart-Harris, R. L., and Nutt, D. J. (2017). Serotonin and brain function: a tale of two receptors. J. Psychopharmacol. 31, 1091-1120.

Carter, O. L., Burr, D. C., Pettigrew, J. D., and Vollenweider, F. X. (2005). Using psilocybin to investigate the relationship between attention, working memory and the serotonin 5-HT1A and 5-HT2A receptors. J. Vis. 5, 683-683. doi: $10.1167 / 5.8 .683$

Chaffiol, A., Ishii, M., Cao, Y., and Mangel, S. C. (2017). Dopamine regulation of GABAA receptors contributes to Light/Dark modulation of the ON-cone bipolar cell receptive field surround in the retina. Curr. Biol. 27, 2600-2609. doi: 10.1016/j.cub.2017.07.063

Chandler, D. J., Waterhouse, B. D., and Gao, W. J. (2014). New perspectives on catecholaminergic regulation of executive circuits: evidence for independent modulation of prefrontal functions by midbrain dopaminergic and noradrenergic neurons. Front. Neural Circ. 8:53. doi: 10.3389/fncir.2014.00053

Choe, H. K., Reed, M. D., Benavidez, N., Montgomery, D., Soares, N., Yim, Y. S., et al. (2015). Oxytocin mediates entrainment of sensory stimuli to social cues of opposing valence. Neuron 87, 152-163. doi: 10.1016/j.neuron.2015.06. 022

Chudasama, Y., and Robbins, T. W. (2004). Dopaminergic modulation of visual attention and working memory in the rodent prefrontal cortex. Neuropsychopharmacology 29, 1628-1636. doi: 10.1038/sj.npp.1300490

Clark, C. R., Geffen, G. M., and Geffen, L. B. (1989). Catecholamines and the covert orientation of attention in humans. Neuropsychologia 27, 131-139. doi: 10.1016/0028-3932(89)90166-8

Clark, K. L., and Noudoost, B. (2014). The role of prefrontal catecholamines in attention and working memory. Front. Neural Circ. 8:33. doi: 10.3389/fncir. 2014.00033

Clark-Elford, R., Nathan, P. J., Auyeung, B., Mogg, K., Bradley, B. P., Sule, A., et al. (2014). Effects of Oxytocin on attention to emotional faces in healthy volunteers and highly socially anxious males. Int. J. Neuropsychopharmacol. 18, 1-7. doi: 10.1093/ijnp/pyu012

Cohen, M. R., and Maunsell, J. H. R. (2009). Attention improves performance primarily by reducing interneuronal correlations. Nat. Neurosci. 12, 1594-1600. doi: $10.1038 / \mathrm{nn} .2439$

Collingridge, G. L., Volianskis, A., Bannister, N., France, G., Hanna, L., Mercier, M., et al. (2013). The NMDA receptor as a target for cognitive enhancement. Neuropharmacology 64, 13-26. doi: 10.1016/j.neuropharm.2012.06.051

Cools, R. (2016). The costs and benefits of brain dopamine for cognitive control. WIREs Cogn. Sci. 7, 317-329. doi: 10.1002/wcs.1401

Corbetta, M., and Shulman, G. L. (2002). Control of goal-directed and stimulusdriven attention in the brain. Nat. Rev. Neurosci. 3, 201-215. doi: 10.1038/ $\operatorname{nrn} 755$

Coull, J. T., Nobre, A. C., and Frith, C. D. (2001). The noradrenergic $\alpha 2$ agonist clonidine modulates behavioural and neuroanatomical correlates of human attentional orienting and alerting. Cereb. Cortex 11, 73-84. doi: 10.1093/cercor/ 11.1 .73

Curic, S., Leicht, G., Thiebes, S., Andreou, C., Polomac, N., Eichler, I. C., et al. (2019). Reduced auditory evoked gamma-band response and schizophrenia-like clinical symptoms under subanesthetic ketamine. Neuropsychopharmacology 44, 1239-1246. doi: 10.1038/s41386-019-0328-5

Dang, L. C., O’Neil, J. P., and Jagust, W. J. (2012). Dopamine supports coupling of attention-related networks. J. Neurosci. 32, 9582-9587. doi: 10.1523/ JNEUROSCI.0909-12.2012

Dasilva, M., Brandt, C., Gotthardt, S., Gieselmann, M. A., Distler, C., and Thiele, A. (2019). Cell class-specific modulation of attentional signals by acetylcholine in macaque frontal eye field. Proc. Natl. Acad. Sci. U.S.A. 116, 20180-20189. doi: 10.1073/pnas. 1905413116

Dauvermann, M. R., Lee, G., and Dawson, N. (2017). Glutamatergic regulation of cognition and functional brain connectivity: insights from pharmacological, genetic and translational schizophrenia research. Br. J. Pharmacol. 174, 31363160. doi: 10.1111/bph.13919

Davidson, M. C., and Marrocco, R. T. (2000). Local infusion of scopolamine into intraparietal cortex slows covert orienting in rhesus monkeys [published correction appears in Journal of Neurophysiology, 2003, 89(6), 3354]. J. Neurophysiol. 83, 1536-1549. doi: 10.1152/jn.2000.83.3.1536

de Jonge, J. C., Vinkers, C. H., Hulshoff Pol, H. E., and Marsman, A. (2017). GABAergic mechanisms in schizophrenia: linking postmortem and in vivo studies. Front. Psychiatry 8:118. doi: 10.3389/fpsyt.2017.00118

De Martino, B., Strange, B. A., and Dolan, R. J. (2008). Noradrenergic neuromodulation of human attention for emotional and neutral stimuli. Psychopharmacology 197, 127-136. doi: 10.1007/s00213-0071015-5 
Deco, G., and Hugues, E. (2012). Neural network mechanisms underlying stimulus driven variability reduction. PLoS Comput. Biol. 8:e1002395. doi: 10.1371/ journal.pcbi. 1002395

Deco, G., and Thiele, A. (2009). Attention - oscillations and neuropharmacology. Eur. J. Neurosci. 30, 347-354. doi: 10.1111/j.1460-9568.2009.06833.x

Deserno, L., Schlagenhauf, F., and Heinz, A. (2016). Striatal dopamine, reward, and decision making in schizophrenia. Dialog. Clin. Neurosci. 18, 77-89.

Disney, A. A., Aoki, C., and Hawken, M. J. (2007). Gain modulation by nicotine in macaque V1. Neuron 56, 701-713.

Dockree, P. M., Barnes, J., Matthews, N., and Dean, A. (2017). The effects of methylphenidate on the neural signatures of sustained attention. Biol. Psychiatry 82, 687-694. doi: 10.1016/j.biopsych.2017.04.016

Domes, G., Heinrichs, M., Kumbier, E., Grossmann, A., Hauenstein, K., and Herpertz, S. C. (2013). Effects of intranasal oxytocin on the neural basis of face processing in autism spectrum disorder. Biol. Psychiatry 74, 164-171. doi: 10.1016/j.biopsych.2013.02.007

Domes, G., Sibold, M., Schulze, L., Lischke, A., Herpertz, S. C., and Heinrichs, M. (2012). Intranasal oxytocin increases covert attention to positive social cues. Psychol. Med. 43, 1747-1753.

Duncan, N. W., Wiebking, C., and Northoff, G. (2014). Associations of regional GABA and glutamate with intrinsic and extrinsic neural activity in humans a review of multimodal imaging studies. Neurosci. Biobehav. Rev. 47, 36-52. doi: 10.1016/j.neubiorev.2014.07.016

Edden, R. A. E., Crocetti, D., Zhu, H., Gilbert, D., and Mostofsky, S. H. (2012). Reduced GABA concentration in attention-deficit/hyperactivity disorder. Arch. Gen. Psychiatry 69, 750-753.

Ehlers, M. R., and Todd, R. M. (2017). Genesis and maintenance of attentional biases: the role of the locus coeruleus-noradrenaline system. Neural Plast. 2017:6817349. doi: 10.1155/2017/6817349

Ellis, J. R., Ellis, K. A., Bartholomeusz, C. F., Harrison, B. J., Wesnes, K. A., Erskine, F. F., et al. (2006). Muscarinic and nicotinic recep-tors synergistically modulate working memory and attention in humans. Int. J. Neuropsychopharmacol. 9, 175-189. doi: 10.1017/S1461145705005407

Enge, S., Fleischhauer, M., Lesch, K. P., Reif, A., and Strobel, A. (2014). Variation in key genes of serotonin and norepinephrine function predicts gamma-band activity during goal-directed attention. Cereb. Cortex 24, 1195-1205. doi: 10. 1093/cercor/bhs398

Enge, S., Fleischhauer, M., Lesch, K. P., and Strobel, A. (2011). On the role of serotonin and effort in voluntary attention: evidence of genetic variation in N1 modulation. Behav. Brain Res. 216, 122-128. doi: 10.1016/j.bbr.2010.07.021

Engel, T. A., Steinmetz, N. A., Gieselmann, M. A., Thiele, A., Moore, T., and Boahen, K. (2016). Selective modulation of cortical state during spatial attention. Science 354, 1140-1144. doi: 10.1126/science.aag1420

Engelmann, J. B., Damaraju, E., Padmala, S., and Pessoa, L. (2009). Combined effects of attention and motivation on visual task performance: transient and sustained motivational effects. Front. Hum. Neurosci. 3:2009. doi: 10.3389/ neuro.09.004.2009

Failing, M., and Theeuwes, J. (2017). Don't let it distract you: how information about the availability of reward affects attentional selection. Attent. Percept. Psychophys. 79, 2275-2298. doi: 10.3758/s13414-017-1376-8

Failing, M., and Theeuwes, J. (2018). Selection history: how reward modulates selectivity of visual attention. Psychon. Bull. Rev. 25, 514-538. doi: 10.3758/ s13423-017-1380-y

Feldmann-Wüstefeld, T., Brandhofer, R., and Schubö, A. (2016). Rewarded visual items capture attention only in heterogeneous contexts. Psychophysiology 53, 1063-1073. doi: 10.1111/psyp.12641

Floresco, S. B., and Magyar, O. (2006). Mesocortical dopamine modulation of executive functions: beyond working memory. Psychopharmacology 188, 567585. doi: 10.1007/s00213-006-0404-5

Foote, S. L., Aston-Jones, G., and Bloom, F. E. (1980). Impulse activity of locus coeruleus neurons in awake rats and monkeys is a function of sensory stimulation and arousal. Proc. Natl. Acad. Sci. U.S.A. 77, 3033-3037.

Frangou, P., Emir, U. E., Karlaftis, V. M., Nettekoven, C., Hinson, E. L., Larcombe, S., et al. (2019). Learning to optimize perceptual decisions through suppressive interactions in the human brain. Nat. Commun. 10, 1-12. doi: 10.1038/s41467019-08313-y
Friedman, J. I. (2004). Cholinergic targets for cognitive enhancement in schizophre-nia: focus on cholinesterase inhibitors and muscarinic agonists. Psychopharmacology 174, 45-53. doi: 10.1007/s00213-004-1794-x

Fries, P. (2005). A mechanism for cognitive dynamics: neuronal communication through neuronal coherence. Trends Cogn. Sci. 9, 474-480. doi: 10.1016/j.tics. 2005.08.011

Fries, P. (2009). Neuronal gamma-band synchronization as a fundamental process in cortical computation. Annu. Rev. Neurosci. 32, 209-224. doi: 10.1146/ annurev.neuro.051508.135603

Fries, P. (2015). Rhythms for cognition: communication through coherence. Neuron 88, 220-235. doi: 10.1016/j.neuron.2015.09.034.Rhythms

Froemke, R. C. (2015). Plasticity of cortical excitatory-inhibitory balance. Annu. Rev. Neurosci. 38, 195-219. doi: 10.1146/annurev-neuro-071714-034002

Fuchs, I., Ansorge, U., Huber-Huber, C., Höflich, A., and Lanzenberger, R. (2015). S-ketamine influences strategic allocation of attention but not exogenous capture of attention. Conscious. Cogn. 35, 282-294. doi: 10.1016/j.concog.2015. 01.009

Furey, M. L., Pietrini, P., Haxby, J. V., and Drevets, W. C. (2008). Selective effects of cholinergic modulation on task performance during selective attention. Neuropsychopharmacology 33, 913-923. doi: 10.1038/sj.npp.1301461

Galvin, V. C., Arnsten, A. F. T., and Wang, M. (2018). Evolution in neuromodulation-the differential roles of acetylcholine in Higher Order Association vs. Primary visual cortices. Front. Neural Circ. 12, 1-14. doi: 10. 3389/fncir.2018.00067

Gamo, N. J., Wamg, M., and Arnsten, A. F. (2010). Methylphenidate and atomoxetine enhance prefrontal function through alpha-2 adrenergic and dopamine D1 receptors. J. Am. Acad. Child Adolesc. Psychiatry 49, 10111023.

Gazzaley, A., and Nobre, A. C. (2012). Top-down modulation: bridging selective attention and working memory. Trends Cogn. Sci. 16, 129-135. doi: 10.1016/j. tics.2011.11.014.Top-down

Gelbard-Sagiv, H., Magidov, E., Sharon, H., Hendler, T., and Nir, Y. (2018). Noradrenaline modulates visual perception and late visually evoked activity. Curr. Biol. 28, 2239-2249.e6. doi: 10.1016/j.cub.2018.05.051

Gielow, M. R., and Zaborszky, L. (2017). The input-output relationship of the cholinergic basal forebrain. Cell Rep. 18, 1817-1830.

Goard, M., and Dan, Y. (2009). Basal forebrain activation enhances cortical coding of natural scenes. Nat. Neurosci. 12, 1444-1449.

Gorgoraptis, N., Mah, Y. H., MacHner, B., Singh-Curry, V., Malhotra, P., HadjiMichael, M., et al. (2012). The effects of the dopamine agonist rotigotine on hemispatial neglect following stroke. Brain 135, 2478-2491. doi: 10.1093/brain/ aws 154

Gotti, C., Zoli, M., and Clementi, F. (2006). Brain nicotinic acetylcholine receptors: native subtypes and their relevance. Trends Pharmacol. Sci. 27, 482-491. doi: 10.1016/j.tips.2006.07.004

Gratton, C., Yousef, S., Aarts, E., Wallace, D. L., D’Esposito, M., and Silver, M. A. (2017). Cholinergic, but not dopaminergic or noradrenergic, enhancement sharpens visual spatial perception in humans. J. Neurosci. 37, 4405-4415. doi: 10.1523/JNEUROSCI.2405-16.2017

Graybiel, A. M. (2008). Habits, rituals, and the evaluative brain. Annu. Rev. Neurosci. 31, 359-387. doi: 10.1146/annurev.neuro.29.051605.112851

Green, A., Ellis, K. A., Ellis, J., Bartholomeusz, C. F., Ilic, S., Croft, R. J., et al. (2005). Muscarinic and nicotinic receptor modulation of object and spatial n-back working memory in humans. Pharmacol. Biochem. Behav. 81, 575-584. doi: 10.1016/j.pbb.2005.04.010

Greenwood, P. M., Fossella, J. A., and Parasuraman, R. (2005). Specificity of the effect of a nicotinic receptor polymorphism on individual differences in visuospatial attention. J. Cogn. Neurosci. 17, 1611-1620. doi: 10.1162/ 089892905774597281

Greenwood, P. M., Lin, M. K., Sundararajan, R., Fryxell, K. J., and Parasuraman, R. (2009). Synergistic effects of genetic variation in nicotinic and muscarinic receptors on visual attention but not working memory. Proc. Natl. Acad. Sci. U.S.A. 106, 3633-3638. doi: 10.1073/pnas.0807891106

Gregoriou, G., Gotts, S., Zhou, H., and Desimone, R. (2009). High-frequency, longrange coupling between prefrontal and visual cortex during attention. Science $324,1207-1210$. 
Gregoriou, G. G., Paneri, S., and Sapountzis, P. (2015). Oscillatory synchrony as a mechanism of attentional processing. Brain Res. 1626, 165-182. doi: 10.1016/j. brainres.2015.02.004

Grinevich, V., and Stoop, R. (2018). Interplay between oxytocin and sensory systems in the orchestration of socio-emotional behaviors. Neuron 99, 887-904. doi: 10.1016/j.neuron.2018.07.016

Gritton, H. J., Howe, W. M., Mallory, C. S., Hetrick, V. L., Berke, J. D., and Sarter, M. (2016). Cortical cholinergic signaling controls the detection of cues. Proc. Natl. Acad. Sci. U.S.A. 113, E1089-E1097. doi: 10.1073/pnas.15161 34113

Grothe, I., Neitzel, S. D., Mandon, S., and Kreiter, A. K. (2012). Switching neuronal inputs by differential modulations of gamma-band phase-coherence. J. Neurosci. 32, 16172-16180. doi: 10.1523/JNEUROSCI.0890-12.2012

$\mathrm{Gu}, \mathrm{Q}$. (2003). Contribution of acetylcholine to visual cortex plasticity. Neurobiol. Learn. Mem. 80, 291-301.

Gunduz-Bruce, H., Reinhart, R. M., Roach, B. J., Gueorguieva, R., Oliver, S., D'Souza, D. C., et al. (2012). Glutamatergic modulation of auditory information processing in the human brain. Biol. Psychiatry 71, 969-977. doi: 10.1016/j.biopsych.2011.09.031

Haber, S. N. (2011). "Chapter 11: neuroanatomy of reward: a view from the ventral striatum," in Neurobiology of Sensation and Reward, ed. J. A. Gottfried (Boca Raton, FL: CRC Press/Taylor \& Francis).

Hahn, B. (2015). "Nicotinic receptors and attention," in The Neurobiology and Genetics of Nicotine and Tobacco, eds D. J. K. Balfour and M. R. Munafò (Berlin: Springer International Publishing), 103-135. doi: 10.1007/978-3-319-13 665-3_5

Hahn, B., Ross, T. J., Wolkenberg, F. A., Shakleya, D. M., Huestis, M. A., and Stein, E. A. (2009). Performance effects of nicotine during selective attention, divided attention, and simple stimulus detection: an fMRI study. Cereb. Cortex 19, 1990-2000. doi: 10.1093/cercor/bhn226

Hahn, B., Shrieves, M. E., Olmstead, C. K., Yuille, M. B., Chiappelli, J. J., Pereira, E. F. R., et al. (2020). Evidence for positive allosteric modulation of cognitiveenhancing effects of nicotine in healthy human subjects. Psychopharmacology 237, 219-230. doi: 10.1007/s00213-019-05363-4

Hampe, C. S., Mitoma, H., and Manto, M. (2018). "GABA and glutamate: their transmitter role in the CNS and pancreatic islets," in GABA and Glutamate, ed. J. Samardzic (London: IntechOpen), doi: 10.5772/intechopen.70958

Harris, K., and Thiele, A. (2012). Cortical state and attention. Nat. Rev. Neurosci. $12,509-523$.

Hasselmo, M. (2005). Expecting the unexpected: modeling of neuromodulation. Neuron 46, 525-526. doi: 10.1016/j.neuron.2005.05.001

Hasselmo, M. E., and McGaughy, J. (2004). High acetylcholine levels set circuit dynamics for attention and encoding and low acetylcholine levels set dynamics for consolidation. Prog. Brain Res. 145, 207-231. doi: 10.1016/S0079-6123(03) 45015-2

Hasselmo, M. E., Wyble, B. P., and Wallenstein, G. V. (1996). Encoding and retrieval of episodic memories: role of cholinergic and GABAergic modulation in the hippocampus. Hippocampus 6, 693-708.

He, B., Yang, L., Wilke, C., and Yuan, H. (2011). Electrophysiological imaging of brain activity and connectivity - challenges and opportunities. IEEE Trans. Biomed. Eng. 58, 1918-1931.

Heishman, S. J., Kleykamp, B. A., and Singleton, E. G. (2010). Metaanalysis of the acute effects of nicotine and smoking on human performance. Psychopharmacology 210, 453-469. doi: 10.1007/s00213-0101848-1

Herrero, J. L., Roberts, M. J., Delicato, L. S., Gieselmann, M. A., Dayan, P., and Thiele, A. (2008). Acetylcholine contributes through muscarinic receptors to attentional modulation in V1. Nature 454, 1110-1114. doi: 10.1038/ nature 07141

Hickey, C., Chelazzi, L., and Theeuwes, J. (2010). Reward changes salience in human vision via the anterior cingulate. J. Neurosci. 30, 11096-11103. doi: 10.1523/JNEUROSCI.1026-10.2010

Hikosaka, O., Takikawa, Y., and Kawagoe, R. (2000). Role of the basal ganglia in the control of purposive saccadic eye movements. Physiol. Rev. 80, 953-978. doi: 10.1152/physrev.2000.80.3.953

Ho, J. M., and Blevins, J. E. (2013). Coming full circle: contributions of central and peripheral oxytocin actions to energy balance. Endocrinology 154, 589-596. doi: $10.1210 /$ en.2012-1751
Horvitz, J. C. (2000). Mesolimbocortical and nigrostriatal dopamine responses to salient non-reward events. Neuroscience 96, 651-656. doi: 10.1016/s03064522(00)00019-1

Howe, W. M., Gritton, H. J., Lusk, N. A., Roberts, E. A., Hetrick, V. L., Berke, J. D., et al. (2017). Acetylcholine release in prefrontal cortex promotes gamma oscillations and theta-gamma coupling during cue detection. J. Neurosci. 37, 3215-3230. doi: 10.1523/JNEUROSCI.2737-16.2017

Hoyer, D., Clarke, D. E., Fozard, J. R., Hartig, P. R., Martin, G. R., Mylecharane, E. J., et al. (1994). International Union of Pharmacology classification of receptors for 5-hydroxytryptamine (Serotonin). Pharmacol. Rev. 46, 157-203.

Hoyer, D., and Martin, G. (1997). 5-HT receptor classification and nomenclature: towards a harmonization with the human genome. Neuropharmacology 36, 419-428. doi: 10.1016/s0028-3908(97)00036-1

Huber, D., Veinante, P., and Stoop, R. (2005). Vasopressin and oxytocin excite distinct neuronal populations in the central amygdala. Science 308, 245-248. doi: $10.1126 /$ science. 1105636

Ito, H. T., and Schuman, E. M. (2008). Frequency-dependent signal transmission and modulation by neuromodulators. Front. Neurosci. 2:138-144. doi: 10.3389/ neuro.01.027.2008

Itti, L., and Koch, C. (2001). Computational modelling of visual attention. Nat. Rev. Neurosci. 2, 194-203.

Javitt, D. C. (2009). When doors of perception close: bottom-up models of disrupted cognition in schizophrenia. Annu. Rev. Clin. Psychol. 5, 249-275. doi: 10.1146/annurev.clinpsy.032408.153502

Jiang, L., Kundu, S., Lederman, J. D., Lopez-Hernandez, G. Y., Ballinger, E. C., Wang, S., et al. (2016). Cholinergic signaling controls conditioned-fear behaviors and enhances plasticity of cortical-amygdala circuits. Neuron 90 , 1057-1070.

Joiner, W. M., Cavanaugh, J., Wurtz, R. H., and Cumming, B. G. (2017). Visual responses in FEF, unlike $\mathrm{V} 1$, primarily reflect when the visual context renders a receptive field salient. J. Neurosci. 37, 9871-9879. doi: 10.1523/JNEUROSCI. 1446-17.2017

Jones, C., Barrera, I., Brothers, S., Ring, R., and Wahlestedt, C. (2017). Oxytocin and social functioning. Dialog. Clin. Neurosci. 19, 193-201.

Joshua, M., Adler, A., and Bergman, H. (2009). The dynamics of dopamine in control of motor behavior. Curr. Opin. Neurobiol. 19, 615-620. doi: 10.1016/ j.conb.2009.10.001

Juárez Olguín, H., Calderón Guzmán, D., Hernández García, E., and Barragán Mejía, G. (2016). The role of dopamine and its dysfunction as a consequence of oxidative stress. Oxid. Med. Cell. Longev. 2016:9730467. doi: 10.1155/2016/ 9730467

Kanamaru, T., and Aihara, K. (2019). Acetylcholine-mediated top-down attention improves the response to bottom-up inputs by deformation of the attractor landscape. PLoS One 14:e223592. doi: 10.1371/journal.pone.02 23592

Kang, J., Huppé-Gourgues, F., and Vaucher, E. (2014). Boosting visual cortex function and plasticity with acetylcholine to enhance visual perception. Front. Syst. Neurosci. 8:172. doi: 10.3389/fnsys.2014.00172

Kang, J. I. L., and Vaucher, E. (2009). Cholinergic pairing with visual activation results in long-term enhancement of visual evoked potentials. PLoS One 4:e5995. doi: 10.1371/journal.pone.0005995

Katsuki, F., and Constantinidis, C. (2012). Early involvement of prefrontal cortex in visual bottom up attention. Nat. Neurosci. 15, 1160-1166.

Katsuki, F., and Constantinidis, C. (2014). Bottom-up and top-down attention: different processes and overlapping neural systems. Neuroscientist 20, 509-521. doi: $10.1177 / 1073858413514136$

Katthagen, T., Kaminski, J., Heinz, A., Buchert, R., and Schlagenhauf, F. (2020). Striatal dopamine and reward prediction error signaling in unmedicated schizophrenia patients. Schizophrenia Bull. 46, 1535-1546. doi: 10.1093/schbul/ sbaa055

Katz, P., and Calin-Jageman, R. (2008). "Neuromodulation," in New Encyclopedia of Neuroscience, ed. L. R. Squire (New York, NY: Academic Press), 497-503. doi: 10.1016/B978-008045046-9.01964-1

Katzner, S., Busse, L., and Carandini, M. (2011). GABA(A) inhibition controls response gain in visual cortex. J. Neurosci. 31, 5931-5941.

Kihara, K., Kondo, H. M., and Kawahara, J. I. (2016). Differential contributions of GABA concentration in frontal and parietal regions to individual differences in 
attentional blink. J. Neurosci. 36, 8895-8901. doi: 10.1523/JNEUROSCI.076416.2016

Kim, G. H., Kang, I., Jeong, H., Park, S., Hong, H., Kim, J., et al. (2019). Low prefrontal GABA levels are associated with poor cognitive functions in professional boxers. Front. Hum. Neurosci. 13:193. doi: 10.3389/fnhum.2019. 00193

Kim, K., Müller, M., Bohnen, N. I., Sarter, M., and Lustig, C. (2017). Thalamic cholinergic innervation makes a specific bottom-up contribution to signal detection: evidence from Parkinson's disease patients with defined cholinergic losses. NeuroImage 149, 295-304. doi: 10.1016/j.neuroimage.2017.02.006. Thalamic

Kim, Y. S., Woo, J., Lee, C. J., and Yoon, B. E. (2017). Decreased Glial GABA and tonic inhibition in cerebellum of mouse model for Attention-Deficit/ Hyperactivity Disorder (ADHD). Exp. Neurobiol. 26, 206-212. doi: 10.5607/en. 2017.26.4.206

Kimura, F., Fukuda, M., and Tsumoto, T. (1999). Acetylcholine suppresses the spread of excitation in the visual cortex revealed by optical recording: possible differential effect depending on the source of input. Eur. J. Neurosci. 11, 3597-3609. doi: 10.1046/j.1460-9568.1999.00779.x

Klaus, A., Alves Da Silva, J., and Costa, R. M. (2019). What, if, and when to move: basal ganglia circuits and self-paced action initiation. Annu. Rev. Neurosci. 42, 459-483. doi: 10.1146/annurev-neuro-072116-031033

Kobayashi, M., Imamura, K., Sugai, T., Onoda, N., Yamamoto, M., Komai, S., et al. (2000). Selective suppression of horizontal propagation in rat visual cortex by norepinephrine. Eur. J. Neurosci. 12, 264-272. doi: 10.1046/j.1460-9568.2000. 00917.x

Koch, C., and Ullman, S. (1985). Shifts in selective visual attention: towards the underlying neural circuity. Hum. Neurobiol. 4, 219-227.

Kocsis, B., Brown, R. E., McCarley, R. W., and Hajos, M. (2013). Impact of ketamine on neuronal network dynamics: translational modeling of schizophreniarelevant deficits. CNS Neurosci. Therap. 19, 437-447.

Kroener, S., Chandler, J. L., Phillips, P. E. M., and Seamans, J. K. (2009). Dopamine modulates persistent synaptic activity and enhances the signal-to-noise ratio in the prefrontal cortex. PLoS One 4:e6507. doi: 10.1371/journal.pone.00 06507

Krystal, J. H., Beiger, A., D’souza, D. C., Anand, A., Charney, D. S., Aghajanian, G. K., et al. (1999). Therapeutic implications of the hyperglutamatergic effects of NMDA antagonists. Neuropsychopharmacology 21, S143-S157. doi: 10.1016/ S0893-133X(99)00102-5

Krystal, J. H., Karper, L. P., Seibyl, J. P., Freeman, G. K., Delaney, R., Bremner, J. D., et al. (1994). Subanesthetic effects of the noncompetitive NMDA antagonist, ketamine, in humans: psychotomimetic, perceptual, cognitive, and neuroendocrine responses. Arch. Gen. Psychiatry 51, 199-214. doi: 10.1001/ archpsyc.1994.03950030035004

LaBar, K. S., Gitelman, D. R., Parrish, T. B., and Mesulam, M. (1999). Neuroanatomic overlap of working memory and spatial attention networks: a functional MRI com-parison within subjects. Neuroimage 10, 695-704. doi: 10.1006/nimg.1999.0503

Labuschagne, I., Phan, K. L., Wood, A., Angstadt, M., Chua, P., Heinrichs, M., et al. (2012). Medial frontal hyperactivity to sad faces in generalized social anxiety disorder and modulation by oxytocin. Int. J. Neuropsychopharmacol. 15, 883-896. doi: 10.1017/S1461145711001489

Lapiz, M. D., and Morilak, D. A. (2006). Noradrenergic modulation of cognitive function in rat medial prefrontal cortex as measured by attentional set shifting capability. Neuroscience 137, 1039-1049. doi: 10.1016/j.neuroscience.2005.09. 031

Laube, I., Matthews, N., Dean, A. J., O'Connell, R. G., Mattingley, J. B., and Bellgrove, M. A. (2017). Scopolamine reduces electrophysiological indices of distractor suppression: evidence from a contingent capture task. Front. Neural Circ. 11:99. doi: 10.3389/fncir.2017.00099

Lee, H. J., Macbeth, A. H., Pagani, J. H., and Young, W. S. (2009). Oxytocin: the great facili-tator of life. Prog. Neurobiol. 88, 127-151. doi: 10.1016/j.pneurobio. 2009.04.001

Lee, M. G., Hassani, O. K., Alonso, A., and Jones, B. E. (2005). Cholinergic basal forebrain neurons burst with theta during waking and paradoxical sleep. J. Neurosci. 25, 4365-4369. doi: 10.1523/JNEUROSCI.0178-05.2005

Lee, S. H., and Dan, Y. (2012). Neuromodulation of brain states. Neuron 76, 209-222. doi: 10.1016/j.neuron.2012.09.012
Leonte, A., Colzato, L. S., Steenbergen, L., Hommel, B., and Akyürek, E. G. (2018). Supplementation of gamma-aminobutyric acid (GABA) affects temporal, but not spatial visual attention. Brain Cogn. 120, 8-16. doi: 10.1016/j.bandc.2017. 11.004

Levitt, P., and Moore, R. Y. (1978). Noradrenaline neuron innervation of the neocortex I the rat. Brain Res. 139, 219-231.

Li, X., Chen, W., Pan, K., Li, H., Pang, P., Guo, Y., et al. (2018). Serotonin receptor $2 \mathrm{c}$-expressing cells in the ventral CA1 control atten-tion via innervation of the Edinger-Westphal nucleus. Nat. Neurosci. 21, 1239-1250. doi: 10.1038/s41593018-0207-0

Li, Y., Zhang, C. C., Weidacker, K., Zhang, Y., He, N., Jin, H., et al. (2019). Investigation of anterior cingulate cortex gamma-aminobutyric acid and glutamate-glutamine levels in obsessive-compulsive disorder using magnetic resonance spectroscopy. BMC Psychiatry 19:164. doi: 10.1186/s12888-0192160-1

Lidow, M. S., Goldman-Rakic, P. S., Gallager, D. W., and Rakic, P. (1991). Distribution of dopaminergic receptors in the primate cerebral cortex: quantitative autoradiographic analysis using [3H]raclopride, $[3 \mathrm{H}]$ spiperone and [3H]SCH23390. Neuroscience 40, 657-671. doi: 10.1016/0306-4522(91) 90003-7

Lindner, M., Bell, T., Iqbal, S., Mullins, P. G., and Christakou, A. (2017). In vivo functional neurochemistry of human Cortical cholinergic function during visuospatial attention. PLoS One 12:e171338. doi: 10.1371/journal. pone. 0171338

Lohani, S., Martig, A. K., Deisseroth, K., Witten, I. B., and Moghaddam, B. (2019). Dopamine modulation of prefrontal cortex activity is manifold and operates at multiple temporal and spatial scales. Cell Rep. 27, 99-114.e6. doi: 10.1016/j. celrep.2019.03.012

Loizou, L. A. (1969). Rostral projections of noradrenaline-containing neurones in the lower brain stem. J. Anat. 104(Pt 3):593.

Lundwall, R. A., Guo, D. C., and Dannemiller, J. L. (2012). Exogenous visual orienting is associated with specific neurotransmitter genetic markers: a population-based genetic association study. PLoS One 7:e30731. doi: 10.1371/ journal.pone.0030731

Ma, S., Hangya, B., Leonard, C. S., Wisden, W., and Gundlach, A. L. (2018). Dual-transmitter systems regulating arousal, attention, learning and memory. Neurosci. Biobehav. Rev. 85, 21-33.

Malhotra, A. K., Pinals, D. A., Weingartner, H., Sirocco, K., Missar, C. D., Pickar, D., et al. (1996). NMDA receptor function and human cognition: the effects of ketamine in healthy volunteers. Neuropsychopharmacology 14, 301-307. doi: 10.1016/0893-133X(95)00137-3

Manns, I. D., Alonso, A., and Jones, B. E. (2000). Discharge properties of juxtacellularly labeled and immunohistochemically identified cholinergic basal forebrain neurons recorded in association with the electroencephalogram in anesthetized rats. J. Neurosci. 20, 1505-1518.

Markovic, J., Anderson, A. K., and Todd, R. M. (2014). Tuning to the significant: neural and genetic processes underlying affective enhancement of visual perception and memory. Behav. Brain Res. 259, 229-241. doi: 10.1016/j.bbr. 2013.11.018

Mather, M., Clewett, D., Sakaki, M., and Harley, C. W. (2016). Norepinephrine ignites local hotspots of neuronal excitation: how arousal amplifies selectivity in perception and memory. Behav. Brain Sci. 39:e200. doi: 10.1017/ S0140525X15000667

Maunsell, J. H. (2004). Neuronal representations of cognitive state: reward or attention? Trends Cogn. Sci. 8, 261-265. doi: 10.1016/j.tics.2004.04.003

Mazade, R. E., Flood, M. D., and Eggers, E. D. (2019). Dopamine D1 receptor activation reduces local inner retinal inhibition to light-adapted levels. J. Neurophysiol. 121, 1232-1243. doi: 10.1152/jn.00448.2018

McGarrity, S., Mason, R., Fone, K. C., Pezze, M., and Bast, T. (2017). Hippocampal neural disinhibition causes attentional and memory deficits. Cereb. Cortex 27, 4447-4462. doi: 10.1093/cercor/bhw247

Meehan, T. P., Bressler, S. L., Tang, W., Astafiev, S. V., Sylvester, C. M., Shulman, G. L., et al. (2017). Top-down cortical interactions in visuospatial attention. Brain Struct. Funct. 222, 3127-3145. doi: 10.1007/s00429-017-1390-6

Meneses, A., and Liy-Salmeron, G. (2012). Serotonin and emotion, learning and memory. Rev. Neurosci. 23, 543-553. doi: 10.1515/revneuro-2012-0060

Mesulam, M. M., Mufson, E. J., Levey, A. I., and Wainer, B. H. (1983). Cholinergic innervation of cortex by the basal forebrain: cytochemistry and cortical 
connections of the septal area, diagonal band nuclei, nucleus basalis (Substantia innominata), and hypothalamus in the rhesus monkey. J. Comp. Neurol. 214, 170-197. doi: 10.1002/cne.902140206

Mesulam, M. M., Mufson, E. J., and Wainer, B. H. (1986). Three-dimensional representation and cortical projection topography of the nucleus basalis (Ch4) in the macaque: concurrent demonstration of choline acetyltransferase and retrograde transport with stabilized tetramethylbenzidine method for horseradish peroxidase. Brain Res. 367, 301-308.

Minces, V., Pinto, L., Dan, Y., and Chiba, A. A. (2017). Cholinergic shaping of neural correlations. Proc. Natl. Acad. Sci. U.S.A. 114, 5725-5730. doi: 10.1073/ pnas. 1621493114

Mirtre, M., Minder, J., and Morina, E. X. (2018). Oxytocin modulation of neural circuits. Curr. Top. Behav. Neurosci. 35, 31-53. doi: 10.1007/7854

Mishkin, M., and Ungerleider, L. G. (1982). Contribution of striate inputs to the visuospatial functions of parieto-preoccipital cortex in monkeys. Behav. Brain Res. 6, 57-77. doi: 10.1016/0166-4328(82)90081-X

Mitchell, J. F., Sundberg, K. A., and Reynolds, J. H. (2009). Spatial attention decorrelates intrinsic activity fluctuations in macaque area V4. Neuron 63, 879-888. doi: 10.1016/j.neuron.2009.09.013

Mohammad-Zadeh, L. F., Moses, L., and Gwaltney-Brant, S. M. (2008). Serotonin: a review. J. Vet. Pharm. Therap. 31, 187-199. doi: 10.1111/j.1365-2885.2008. 00944.x

Moore, H., Sarter, M., and Bruno, J. P. (1995). Bidirectional modulation of cortical acetylcholine efflux by infusion of benzodiazepine receptor ligands into the basal forebrain. Neurosci. Lett. 189, 31-34. doi: 10.1016/0304-3940(95) 11444-2

Moore, T., and Zirnsak, M. (2017). Neural mechanisms of selective visual attention. Annu. Rev. Psychol. 68, 47-72. doi: 10.1146/annurev-psych-122414033400

Morgan, C., Mofeez, A., Brandner, B., Brombey, L., and Curran, V. (2004). Acute effects of ketamine on memory systems and psychotic symptoms in healthy volunteers. Neuropsychopharmacology 29, 208-218. doi: 10.1038/sj.npp. 1300342

Morgan, C. J., and Curran, H. V. (2006). Acute and chronic effects of ketamine upon human memory: a review. Psychopharmacology (Berl.) 188, 408-424. doi: 10.1007/s00213-006-0572-3

Mueller, A., Krock, R. M., Shepard, S., and Moore, T. (2020). Dopamine receptor expression among local and visual cortex-projecting frontal eye field neurons. Cereb. Cortex 30, 148-164. doi: 10.1093/cercor/bhz078

Müller, U., Suckling, J., Zelaya, F., Honey, G., Faessel, H., Williams, S. C., et al. (2005). Plasma level-dependent effects of methylphenidate on task-related functional magnetic resonance imaging signal changes. Psychopharmacology (Berl.) 180, 624-633. doi: 10.1007/s00213-005-2264-9

Murphy, F. C., and Klein, R. M. (1998). The effects of nicotine on spatial and nonspatial expectancies in a covert orienting task. Neuropsychologia 36, 1103-1114. doi: 10.1016/S0028-3932(98)00012-8

Murthy, V. N., and Fetz, E. E. (1994). Effects of input synchrony on the firing rate of a three-conductance cortical neuron model. Neural Comput. 6, 1111-1126. doi: 10.1162/neco.1994.6.6.1111

Musso, F., Brinkmeyer, J., Ecker, D., London, M., Thieme, G., Warbrick, T., et al. (2011). Ketamine effects on brain function-simultaneous $\mathrm{fMRI} / \mathrm{EEG}$ during a visual oddball task. Neuroimage 58, 508-525. doi: 10.1016/j.neuroimage.2011. 06.045

Nadim, F., and Bucher, D. (2014). Neuromodulation of neurons and synapses. Curr. Opin. Neurobiol. 0, 48-56.

Neuhaus, A. H., Karl, C., Hahn, E., Trempler, N. R., Opgen-Rhein, C., Urbanek, C., et al. (2011). Dissection of early bottom-up and top-down deficits during visual attention in schizophrenia. Clin. Neurophysiol. 122, 90-98. doi: 10.1016/ j.clinph.2010.06.011

Newman, E. L., Gupta, K., Climer, J. R., Monaghan, C. K., and Hasselmo, M. E. (2012). Cholinergic modulation of cognitive processing: insights drawn from computational models. Front. Behav. Neurosci. 6:24. doi: 10.3389/fnbeh.2012. 00024

Nieoullon, A. (2002). Dopamine and the regulation of cognition and attention. Prog. Neurobiol. 67, 53-83. doi: 10.1016/s0301-0082(02)00011-4

Nieuwenhuis, S., van Nieuwpoort, I. C., Veltman, D. J., and Drent, M. L. (2007). Effects of the noradrenergic agonist clonidine on temporal and spatial attention. Psychopharmacology (Berl.) 193, 261-269.
Noudoost, B., Chang, M. H., Steinmetz, N. A., and Moore, T. (2010). Top-down control of visual attention. Curr. Opin. Neurobiol. 20, 183-190.

Noudoost, B., and Moore, T. (2011). Control of visual cortical signals by prefrontal dopamine. Nature 474, 372-375. doi: 10.1038/nature09995

Noudoost, B., and Moore, T. (2012). The role of neuromodulators in selective attention. Trends Cogn. Sci. 15, 585-591.

O’Donnell, J., Zeppenfeld, D., Mcconnell, E., Pena, S., and Nedergaard, M. (2012). Norepinephrine: a neuromodulator that boosts the function of multiple cell types to optimize CNS performance. Neurochem. Res. 37, 2496-2512. doi: 10. 1007/s11064-012-0818-x.Norepinephrine

Oettl, L. L., Ravi, N., Schneider, M., Scheller, M. F., Schneider, P., Mitre, M., et al. (2016). Oxytocin enhances social recognition by modulating cortical control of early olfactory processing. Neuron 90, 609-621. doi: 10.1016/j.neuron.2016. 03.033

Oranje, B., van Berckel, B. N., Kemner, C., van Ree, J. M., and Kahn, R. S. (2000). The effects of a sub-anaesthetic dose of ketamine on human selective attention. Neuropsychopharmacology 22, 293-302. doi: 10.1016/S0893-133X(99) 00118-9

Paine, T. A., Slipp, L. E., and Carlezon, W. A. (2011). Schizophrenia-like attentional deficits following blockade of prefrontal cortex GABA a receptors. Neuropsychopharmacology 36, 1703-1713. doi: 10.1038/npp.2011.51

Paneri, S., and Gregoriou, G. G. (2017). Top-down control of visual attention by the prefrontal cortex. Functional specialization and long-range interactions. Front. Neurosci. 11:1-16. doi: 10.3389/fnins.2017.00545

Paolone, G., Howe, W., Gopalakrishnan, M., Decker, M. W., and Sarter, M. (2010). "Regulation and function of the tonic component of cortical acetylcholine release," in Monitoring Molecules in Neuroscience, eds B. Westerink, R. Clinckers, I. Smolders, S. Sarre, and Y. Michotte (Brussels: Vrije Universiteit Brussels), 363-365.

Parasuraman, R., Greenwood, P. M., Kumar, R., and Fossella, J. A. (2005). Beyond heritability: neurotransmiter genes differentially modulate visuospatial attention and working memory. Psychol. Sci. 16, 200-207.

Parikh, V., and Sarter, M. (2008). Cholinergic mediation of attention: contributions of phasic and tonic increases in prefrontal cholinergic activity. Ann. N. Y. Acad. Sci. 1129, 225-235. doi: 10.1196/annals.1417.021

Peck, C. J., Jangraw, D. C., Suzuki, M., Efem, R., and Gottlieb, J. (2009). Reward modulates attention independently of action value in posterior parietal cortex. J. Neurosci. 29, 11182-11191. doi: 10.1523/JNEUROSCI.1929-09.2009

Pessoa, L. (2015). Multiple influences of reward on perception and attention. Vis. Cogn. 23, 272-290. doi: 10.1080/13506285.2014.974729.Multiple

Petersen, S. E., Robinson, D. L., and Morris, H. D. (1987). Contributions of the pulvinar to visual spatial attention. Neuropsychologia 25, 97-105. doi: 10.1016/ 0028-3932(87)90046-7

Pezze, M., McGarrity, S., Mason, R., Fone, K. C., and Bast, T. (2014). Too little and too much: hypoactivation and disinhibition of medial prefrontal cortex cause attentional deficits. J. Neurosci. 34, 7931-7946. doi: 10.1523/JNEUROSCI.345013.2014

Picciotto, M. R., Higley, M. J., and Mineur, Y. S. (2012). Acetylcholine as a neuromodulator. Neuron 76, 116-129. doi: 10.1016/j.neuron.2012.08.036. Acetylcholine

Poorthuis, R. B., Bloem, B., Schak, B., Wester, J., de Kock, C., and Mansvelder, H. D. (2013). Layer-specific modulation of the prefrontal cortex by nicotinic acetylcholine receptors. Cereb. Cortex 23, 148-161. doi: 10.1093/cercor/bhr390

Prinzmetal, W., Rokem, A., Landau, A., Wallace, D., Silver, M. D., and Esposito, M. (2010). The D2 dopa-mine receptor agonist bromocriptine enhances voluntary but not involuntary spatial attention in hu-mans. J. Vis. 10:155. doi: 10.1167/10. 7.155

Puglia, M. H., Connelly, J. J., and Morris, J. P. (2018). Epigenetic regulation of the oxytocin receptor is associated with neural response during selective social attention. Transl. Psychiatry 8:116. doi: 10.1038/s41398-018-0159-x

Puig, M. V., and Gulledge, A. T. (2011). Serotonin and prefrontal cortex function: neurons, networks, and circuits. Mol. Neurobiol. 44, 449-464. doi: 10.1007/ s12035-011-8214-0

Rabinowitz, N. C., Goris, R. L., Cohen, M., and Simoncelli, E. P. (2015). Attention stabilizes the shared gain of V4 populations. eLife 4:e08998. doi: 10.7554/eLife. 08998

Raichle, M. E. (2015). The Brain's default mode network. Annu. Rev. Neurosci. 38, 433-447. doi: 10.1146/annurev-neuro-071013-014030 
Raichle, M. E., MacLeod, M. A., Snyder, A. Z., Powers, W. J., Gusnard, D. A., and Shulman, G. L. (2001). A default mode of brain function. Proc. Natl. Acad. Sci. U.S.A. 98, 676-682. doi: 10.1073/pnas.98.2.676

Ranganath, A., and Jacob, S. N. (2016). Doping the mind: dopaminergic modulation of prefrontal cortical cognition. Neuroscientist 22, 593-603. doi: $10.1177 / 1073858415602850$

Ranjbar-Slamloo, Y., and Fazlali, Z. (2020). Dopamine and noradrenaline in the brain; overlapping or dissociate functions? Front. Mol. Neurosci. 12:334. doi: 10.3389/fnmol.2019.00334

Ricciardi, E., Handjaras, G., Bernardi, G., Pietrini, P., and Furey, M. L. (2013). Cholinergic enhancement reduces functional connectivity and BOLD variability in visual extrastriate cortex during selective attention. Neuropharmacology 64, 305-313.

Richter, C. G., Thompson, W. H., Bosman, C. A., and Fries, P. (2017). Top-down beta enhances bottom-up gamma. J. Neurosci. 37, 6698-6711. doi: 10.1523/ jneurosci.3771- 16.2017

Riddle, J., Hwang, K., Dillan, C., Dhanani, S., and D’Esposito, M. (2019). Causal evidence for the role of neuronal oscillations in top- down and bottom-up attention. J. Cogn. 31, 768-779. doi: 10.1162/jocn

Robbins, T. W. (2002). The 5-choice serial reaction time task: behavioral pharmacology and functional neurochemistry. Psychopharmacology 163, 362380. doi: 10.1007/s00213-002-1154-7

Robbins, T. W., and Arnsten, A. F. (2009). The neuropsychopharmacology of fronto-executive function: monoaminergic modulation. Annu. Rev. Neurosci. 32, 267-287. doi: 10.1146/annurev.neuro.051508. 135535

Roberts, M. J., Zinke, W., Guo, K., Robertson, R., McDonald, J. S., and Thiele, A. (2007). Acetylcholine dynamically controls spatial integration in marmoset primary visual cortex. J. Neurophysiol. 93, 2062-2072.

Robison, L. S., Ananth, M., Hadjiargyrou, M., Komatsu, D. E., and Panayotis, T. (2017). Chronic oral methylphenidate treatment reversibly increases striatal dopamine transporter and dopamine type 1 receptor binding in rats Lisa. J. Neural Trans. 124, 665-667. doi: 10.1111/j.1369-1600.2009. 00168.x

Rokem, A., Landau, A. N., Garg, D., Prinzmetal, W., and Silver, M. A. (2010). Cholinergic enhancement increases the effects of voluntary attention but does not affect involuntary attention. Neuropsychopharmacology 35, 2538-2544. doi: 10.1038/npp. 2010.118

Rokem, A., Landau, A. N., Prinzmetal, W., Wallace, D. L., Silver, M. A., and D'Esposito, M. (2012). Modulation of inhibition of return by the dopamine D2 receptor agonist bromocriptine depends on individual DAT1 genotype. Cereb. Cortex 22, 1133-1138. doi: 10.1093/cercor/bhr185

Rosburg, T., and Schmidt, A. (2018). Potential mechanisms for the ketamineinduced reduction of P3b amplitudes. Front. Behav. Neurosci. 12:308. doi: 10. 3389/fnbeh.2018.00308

Ross, H. E., and Young, L. J. (2009). Oxytocin and the neural mechanisms regulating social cognition and affiliative behavior. Front. Neuroendocrinol. 30:534-547. doi: 10.1016/j.yfrne.2009.05.004

Roy, S., and Field, G. D. (2019). Dopaminergic modulation of retinal processing from starlight to sunlight. J. Pharmacol. Sci. 140, 86-93. doi: 10.1016/j.jphs. 2019.03.006

Sajedin, A., Menhaj, M. B., Vahabie, A. H., Panzeri, S., and Esteky, H. (2019). Cholinergic modulation promotes attentional modulation in primary visual cortex- a modeling study. Sci. Rep. 9, 1-18. doi: 10.1038/s41598-01956608-3

Sakurai, A., and Katz, P. S. (2009). State-, timing-, and patterndependent neuromodulation of synaptic strength by a serotonergic interneuron. J. Neurosci. 29, 268-279. doi: 10.1523/JNEUROSCI.4456-08. 2009

Sandberg, K., Blicher, J. U., Dong, M. Y., Rees, G., Near, J., and Kanai, R. (2014). Occipital GABA correlates with cognitive failures in daily life. NeuroImage 87, 55-60. doi: 10.1016/j.neuroimage.2013.10.059

Sapountzis, P., and Gregoriou, G. G. (2018). Neural signatures of attention: insights from decoding population activity patterns. Front. Biosci. (Landmark Ed.) 23:221-246. doi: $10.2741 / 4588$

Sara, S. J., and Bouret, S. (2012). Orienting and reorienting: the locus coeruleus mediates cognition through arousal. Neuron 76, 130-141. doi: 10.1016/j. neuron.2012.09.011
Sarter, M. (1994). Neuronal mechanisms of the attentional dysfunctions in senile dementia and schizophrenia: two sides of the same coin? Psychopharmacology 114, 539-550. doi: 10.1007/BF02244983

Sarter, M., Givens, B., and Bruno, J. P. (2001). The cognitive neuroscience of sustained attention: Where top-down meets bottom-up. Brain Res. Rev. 35, 146-160. doi: 10.1016/S0165-0173(01)00044-3

Sarter, M., and Lustig, C. (2019). Cholinergic double duty: cue detection and attentional control. Curr. Opin. Psychol. 29, 102-107. doi: 10.1016/j.copsyc. 2018.12.026

Sarter, M., Lustig, C., Blakely, R. D., and Cherian, A. K. (2016). Cholinergic genetics of visual attention: human and mouse choline transporter capacity variants influence distractibility Martin. J. Physiol. Paris 110, 10-18.

Sarter, M., and Parikh, V. (2005). Choline transporters, cholinergic trans-mission and cognition. Nat. Rev. Neurosci. 6, 48-56. doi: 10.1038/nrn1588

Sarter, M., Parikh, V., and Howe, W. M. (2009). Phasic acetylcholine release and the volume transmission hypothesis: time to move on. Nat. Rev. Neurosci. 10, 383-390.

Saunders, A., Granger, A. J., and Sabatini, B. L. (2015). Corelease of acetylcholine and GABA from cholinergic forebrain neurons. eLife 4, 1-13. doi: 10.7554/eLife. 06412

Sawaguchi, T., and Goldman-Rakic, P. S. (1994). The role of D1-dopamine receptor in working memory: local injections of dopamine antagonists into the prefrontal cortex of rhesus monkeys performing an oculomotor delayed-response task. J. Neurophysiol. 71, 515-528.

Schmidt-Wilcke, T., Fuchs, E., Funke, K., Vlachos, A., Müller-Dahlhaus, F., Puts, N. A. J., et al. (2018). GABA - from inhibition to cognition: emerging concepts. Neuroscientist 24, 501-515. doi: 10.1177/1073858417734530

Schneidt, A., Jusyte, A., Rauss, K., and Schönenberg, M. (2018). Distraction by salient stimuli in adults with attention-deficit/hyperactivity disorder: evidence for the role of task difficulty in bottom-up and top-down processing. Cortex 101, 206-220. doi: 10.1016/j.cortex.2018.01.021

Scholes, K. E., Harrison, B. J., O’Neill, B. V., Leung, S., Croft, R. J., Pipingas, A., et al. (2007). Acute serotonin and dopamine depletion improves attentional control: findings from the Stroop task. Neuropsychopharmacology 32, 1600-1610. doi: 10.1038/sj.npp.1301262

Schott, B. H., Minuzzi, L., Krebs, R. M., Elmenhorst, D., Lang, M., Winz, O. H., et al. (2008). Mesolimbic functional magnetic resonance imaging activations during reward anticipation correlate with reward-related ventral striatal dopamine release. J. Neurosci. 28, 14311-14319. doi: 10.1523/JNEUROSCI.2058-08.2008

Schultz, W. (1998). Predictive reward signal of dopamine neurons. J. Neurophysiol. 80, 1-27. doi: 10.1152/jn.1998.80.1.1

Schür, R. R., Draisma, L. W., Wijnen, J. P., Boks, M. P., Koevoets, M., Joels, M., et al. (2016). Brain GABA levels across psychiatric disorders: a systematic literature review and meta-analysis of (1) H-MRS studies. Hum. Brain Mapp. 37, 3337-3352. doi: 10.1002/hbm.23244

Schwertner, A., Zortea, M., Torres, F. V., and Caumo, W. (2018). Effects of subanesthetic ketamine administration on visual and auditory event-related potentials (ERP) in humans: a systematic review. Front. Behav. Neurosci. 12:70. doi: $10.3389 /$ fnbeh.2018.00070

Seamans, J. K., and Yang, C. R. (2004). The principal features and mechanisms of dopamine modulation in the pre-frontal cortex [published correction appears in Progress in Neurobiology. 2004 Dec;74(5):321]. Prog. Neurobiol. 74, 1-58. doi: 10.1016/j.pneurobio.2004.05.006

Seeman, P., and Madras, B. (1998). Anti-hyperactivity medication: methylphenidate and amphetamine. Mol. Psychiatry 3, 386-396.

Serences, J. T., and Yantis, S. (2006). Selective visual attention and perceptual coherence. Trends Cogn. Sci. 10, 38-45. doi: 10.1016/j.tics.2005.11.008

Servan-Schreiber, D., Printz, H., and Cohen, J. D. (1990). A network model of catecholamine effects: gain, signal-to-noise ratio, and behavior. Science 24, $892-895$.

Shalev, N., Vangkilde, S., Neville, M. J., Tunbridge, E. M., Nobre, A. C., and Chechlacz, M. (2019). Dissociable catecholaminergic modulation of visual attention: differential effects of Catechol-O-Methyltransferase and dopamine beta-hydroxylase genes on visual attention. Neuroscience 412, 175-189. doi: 10.1016/j.neuroscience.2019.05.068

Siggins, G. R. (1979). "Neurotransmitters and neuromodulators and their mediation by cyclic nucleotides," in Modulators, Mediators, and Specifiers in Brain Function. Advances in Experimental Medicine and Biology, Vol. 116, eds 
Y. H. Ehrlich, J. Volavka, L. G. Davis, and E. G. Brunngraber (Boston, MA: Springer), doi: 10.1007/978-1-4684-3503-0_3

Snyder, K., Wang, W. W., Han, R., McFadden, K., and Valentino, R. J. (2012). Corticotropin-releasing factor in the norepinephrine nucleus, locus coeruleus, facilitates behavioral flexibility. Neuropsychopharmacology 37, 520-530. doi: 10.1038/npp.2011.218

Soltani, A., Noudoost, B., and Moore, T. (2013). Dopaminergic control of target selection. Proc. Natl. Acad. Sci. U.S.A. 110, 3579-3584. doi: 10.1073/pnas. 1221236110

Sparing, R., and Mottaghy, F. M. (2008). Noninvasive brain stimulation with transcranial magnetic or direct current stimulation (TMS/tDCS)-From insights into human memory to therapy of its dysfunction. Methods 44, 329-337. doi: 10.1016/j.ymeth.2007.02.001

Spreng, N. R., Stevens, D. W., Chamberlain, J. P., Gilmore, A. W., and Schacter, D. L. (2010). Default network activity, coupled with the frontoparietal control network, supports goal-directed cognition. NeuroImage 53, 303-317.

St. Peters, M., Demeter, E., Lustig, C., Bruno, J. P., and Sarter, M. (2011). Enhanced control of attention by stimulating mesolimbic-corticopetal cholinergic circuitry. J. Neurosci. 31, 9760-9771. doi: 10.1523/JNEUROSCI.1902-11.2011

Steenbergen, L., Sellaro, R., Stock, A. K., Beste, C., and Colzato, L. S. (2015). $\gamma$-Aminobutyric acid (GABA) administration improves action selection processes: a randomised controlled trial. Sci. Rep. 5, 1-7. doi: 10.1038/ srep 12770

Steinberg, E. E., Keiflin, R., Boivin, J., Witten, I. B., Deisseroth, K., and Janak, P. H. (2013). A causal link between prediction errors, dopamine neurons and learning. Nat. Neurosci. 16, 966-973. doi: 10.1038/nn.3413.A

Stiedl, O., Pappa, E., Konradsson-Geuken, ̊̊, and Ögren, S. O. (2015). The role of the serotonin receptor subtypes 5-HT1A and 5-HT7 and its interaction in emotional learning and memory. Front. Pharmacol. 6:162. doi: 10.3389/fphar. 2015.00162

Stinear, C. M., and Byblow, W. D. (2003). Role of intracortical inhibition in selective hand muscle activation. J. Neurophysiol. 89, 2014-2020. doi: 10.1152/ jn.00925.2002

Stoop, R. (2012). Neuromodulation by oxytocin and vasopressin. Neuron 76, 142-159. doi: 10.1016/j.neuron.2012.09.025

Strosberg, A. D. (1993). Structure, function, and regulation of adrenergic receptors. Protein Sci. 2, 1198-1209. doi: 10.1002/pro.5560020802

Theeuwes, J., Belopolsky, A., and Olivers, C. N. L. (2009). Interactions between working memory, attention and eye movements. Acta Psychol. 132, 106-114. doi: 10.1016/j.actpsy.2009.01.005

Thiebes, S., Steinmann, S., Curic, S., Polomac, N., Andreou, C., Eichler, I., et al. (2018). Alterations in interhemispheric gamma-band connectivity are related to the emergence of auditory verbal hallucinations in healthy subjects during NMDA-receptor blockade. Neuropsychopharmacology 43, 1608-1615. doi: 10. 1038/s41386-018-0014-z

Thiel, C., Zilles, K., and Fink, G. (2005). Nicotine modulates reorienting of visuospatial attention and neural activity in human parietal cortex. Neuropsychopharmacology 30, 810-820. doi: 10.1038/sj.npp.1300633

Thiele, A. (2013). Muscarinic signaling in the brain. Annu. Rev. Neurosci. 36, 271-294. doi: 10.1146/annurev-neuro-062012-170433

Thiele, A., and Bellgrove, M. A. (2018). Neuromodulation of attention. Neuron 97, 769-785. doi: 10.1016/j.neuron.2018.01.008

Thompson, K. G., and Bichot, N. P. (2005). A visual salience map in the primate frontal eye field. Prog. Brain Res. 147, 249-262. doi: 10.1016/S0079-6123(04) 47019-8

Tognarelli, J. M., Dawood, M., Shariff, M. I. F., Grover, V. P. B., Crossey, M. M. E., Cox, I. J., et al. (2015). Magnetic resonance spectroscopy: principles and techniques: lessons for clinicians. J. Clin. Exp. Hepatol. 5, 320-328. doi: 10.1016/ j.jceh.2015.10.006

Tollenaar, M. S., Chatzimanoli, M., van der Wee, N. J. A., and Putman, P. (2013). Enhanced orienting of attention in response to emotional gaze cues after oxytocin administration in healthy young men. Psychoneuroendocrinology 38 , 1797-1802. doi: 10.1016/j.psyneuen.2013.02.018

Tomasi, D., Volkow, N. D., Wang, G. J., Wang, R., Telang, F., Caparelli, E. C., et al. (2011). Methylphenidate enhances brain activation and deactivation responses to visual attention and working memory tasks in healthy controls. Neuroimage 54, 3101-3110. doi: 10.1016/j.neuroimage.2010.10.060
Tomasi, D., Volkow, N. D., Wang, R., Telang, F., Wang, G. J., Chang, L., et al. (2009). Dopamine transporters in striatum correlate with deactivation in the default mode network during visuospatial attention. PLoS One 4:e6102. doi: 10.1371/journal.pone.0006102

Uhlhaas, P. J., Pipa, G., Neuenschwander, S., Wibral, M., and Singer, W. (2011). A new look at gamma? High- $(>60 \mathrm{~Hz}) \gamma$-band activity in cortical networks: function, mechanisms and impairment. Prog. Biophys. Mol. Biol. 105, 14-28. doi: 10.1016/j.pbiomolbio.2010.10.004

Umbricht, D., Koller, R., Vollenweider, F. X., and Schmid, L. (2002). Mismatch negativity predicts psychotic experiences induced by NMDA receptor antagonist in healthy volunteers. Biol. Psychiatry 51, 400-406. doi: 10.1016/ s0006-3223(01)01242-2

Unal, C. T., Pare, D., and Zaborszky, L. (2015). Impact of basal forebrain cholinergic inputs on basolateral amygdala neurons. J. Neurosci. 35, 853-863. doi: 10.1523/JNEUROSCI.2706-14.2015

Ungerleider, L. G., and Haxby, J. V. (1994). 'What' and 'where' in the human brain. Curr. Opin. Neurobiol. 4, 157-165. doi: 10.1016/0959-4388(94) 90066-3

Uno, Y., and Coyle, J. T. (2019). Glutamate hypothesis in schizophrenia. Psychiatry Clin. Neurosci. 73, 204-215. doi: 10.1111/pcn.12823

Valtcheva, S., and Venance, L. (2019). Control of long-term plasticity by glutamate transporters. Front. Synap. Neurosci. 11:10. doi: 10.3389/fnsyn.2019. 00010

van Es, M. W. J., and Schoffelen, J. M. (2019). Stimulus-induced gamma power predicts the amplitude of the subsequent visual evoked response. NeuroImage 186, 703-712. doi: 10.1016/j.neuroimage.2018.11.029

van Loon, A. M., Knapen, T., Scholte, H. S., St. John-Saaltink, E., Donner, T. H., and Lamme, V. A. F. (2013). GABA shapes the dynamics of bistable perception. Curr. Biol. 23, 823-827. doi: 10.1016/j.cub.2013.03.067

van Wageningen, H., Jørgensen, H. A., Specht, K., and Hugdahl, K. (2010). A ${ }^{1} \mathrm{H}-\mathrm{MR}$ spectroscopy study of changes in glutamate and glutamine (Glx) concentrations in frontal spectra after administration of memantine. Cereb. Cortex 20, 798-803. doi: 10.1093/cercor/bhp145

Vander Weele, C. M., Siciliano, C. A., Matthews, G. A., Namburi, P., Izadmehr, E. M., Espinel, I. C., et al. (2018). Dopamine enhances signal-to-noise ratio in cortical-brainstem encoding of aversive stimuli. Nature 563, 397-401. doi: 10.1038/s41586-018-0682-1

Vangkilde, S., Bundesen, C., and Coull, J. T. (2011). Prompt but inefficient: nicotine differentially modulates discrete components of attention. Psychopharmacology 218, 667-680. doi: 10.1007/s00213-011-2361-x

Vankov, A., Hervé-Minvielle, A., and Sara, S. J. (1995). Response to novelty and its rapid habituation in locus coeruleus neurons of the freely exploring rat. Eur. J. Neurosci. 7, 1180-1187. doi: 10.1111/j.1460-9568.1995.tb0 1108.x

Vitay, J., and Hamker, F. H. (2007). On the role of dopamine in cognitive vision. Lect. Notes Comput. Sci. 4840, 352-366. doi: 10.1007/978-3-540-773 43-6_23

von Düring, F., Ristow, I., Li, M., Denzel, D., Colic, L., Demenescu, L. R., et al. (2019). Glutamate in salience network predicts BOLD response in default mode network during salience processing. Front. Behav. Neurosci. 13:232. doi: 10. 3389/fnbeh.2019.00232

Voytko, M. L., Olton, D. S., Richardson, R. T., Gorman, L. K., Tobin, J. R., and Price, D. L. (1994). Basal forebrain lesions in monkeys disrupt attention but not learning and memory. J. Neurosci. 14, 167-186. doi: 10.1523/jneurosci.14-0100167.1994

Vyklicky, V., Korinek, M., Smejkalova, T., Balik, A., Krausova, B., Kaniakova, M., et al. (2014). Structure, function, and pharmacology of NMDA receptor channels. Physiol. Res. 63(Suppl. 1), S191-S203. doi: 10.33549/physiolres. 932678

Waelti, P., Dickinson, A., and Schultz, W. (2001). Dopamine responses comply with basic assumptions of formal learning theory. Nature 412, 43-48. doi: $10.1038 / 35083500$

Walker, E. P., and Tadi, P. (2020). Neuroanatomy, Nucleus Raphe. Treasure Island (FL): StatPearls Publishing.

Wang, G. J., Volkow, N. D., Wigal, T., Kollins, S. H., Newcorn, J. H., Telang, F., et al. (2013). Long-term stimulant treatment affects brain dopamine transporter level in patients with attention deficit hyperactive disorder. PLoS One 8:e63023. doi: 10.1371/journal.pone.0063023 
Ward, N. M., and Brown, V. J. (1996). Covert orienting of attention in the rat and the role of striatal dopamine. J. Neurosci. 16, 3082-3088. doi: 10.1523/jneurosci. 16-09-03082.1996

Watson, T. D., Petrakis, I. L., Edgecombe, J., Perrino, A., Krystal, J. H., and Mathalon, D. H. (2009). Modulation of the cortical processing of novel and target stimuli by drugs affecting glutamate and GABA neurotransmission. Int. J. Neuropsychopharmacol. 12, 357-370. doi: 10.1017/S1461145708009334

Weinberger, N. M. (2007). Auditory associative memory and representational plasticity in the primary auditory cortex. Hear Res. 229, 54-68.

Wingen, M., Kuypers, K. P., van de Ven, V., Formisano, E., and Ramaekers, J. G. (2008). Sustained attention and serotonin: a pharmaco-fMRI study. Hum. Psychopharmacol. 23, 221-230. doi: 10.1002/hup.923

Witkovsky, P. (2004). Dopamine and retinal function. Doc. Ophthalmol. 108, 17-39. doi: 10.1023/B:DOOP.0000019487.88486.0a

Witte, E. A., Davidson, M. C., and Marrocco, R. T. (1997). Effects of altering brain cholinergic activity on covert orienting of attention: comparison of monkey and human performance. Psychopharmacology 132, 324-334. doi: 10.1007/ s002130050352

Woolf, N. J. (1991). Cholinergic systems in mammalian brain and spinal cord. Prog. Neurobiol. 37, 475-524. doi: 10.1016/0301-0082(91)90006-m

Worbe, Y., Savulich, G., Voon, V., Fernandez-Egea, E., and Robbins, T .W. (2014). Serotonin depletion induces 'waiting impulsivity' on the human four-choice serial reaction time task: cross-species translational significance. Neuropsychopharmacology 39, 1519-1526. doi: 10.1038/npp.2013.351

Wu, F., Liu, M., Chen, C., Chen, J., and Tan, Q. (2016). Effects of dietary gamma aminobutyric acid on growth performance, antioxidant status, and feedingrelated gene expression of juvenile grass carp, Ctenopharyngodon idellus. J. World Aquacult. Soc. 47, 820-829. doi: 10.1111/jwas.12327

Wu, H., Williams, J., and Nathans, J. (2014). Complete morphologies of basal forebrain cholinergic neurons in the mouse. eLife 2014, 1-17. doi: 10.7554/eLife. 02444

Xin, F., Zhou, F., Zhou, X., Ma, X., Geng, Y., Zhao, W., et al. (2018). Oxytocin modulates the intrinsic dynamics between attention-related largescale networks. Cereb. Cortex 31, 1848-1860. doi: 10.1093/cercor/bhy295

Xing, B., Li, Y. C., and Gao, W. J. (2016). Norepinephrine versus dopamine and their interaction in modulating synaptic function in the prefrontal cortex. Brain Res. 1641(Pt B), 217-233. doi: 10.1016/j.brainres.2016.01.005

Yakel, J. L. (2013). Cholinergic receptors: functional role of nicotinic ACh receptors in brain circuits and disease. Pflügers Archiv 465, 441-450.

Yang, C. R., and Seamans, J. K. (1996). Dopamine D1 receptor actions in layers V-VI rat prefrontal cortex neurons in vitro: modulation of dendritic-somatic signal integration. J. Neurosci. 16, 1922-1935. doi: 10.1523/jneurosci.16-0501922.1996

Yoon, J. H., Grandelis, A., and Maddock, R. J. (2016). Dorsolateral prefrontal cortex GABA concentration in humans predicts working memory load processing capacity. J. Neurosci. 36, 11788-11794. doi: 10.1523/JNEUROSCI.1970-16 2016

Yousif, N., Fu, R. Z., Bourquin, A. B., Bhrugubanda, V., Schultz, S. R., and Seemungal, B. M. (2016). Dopamine activation preserves visual motion perception despite noise interference of human v5/mt. J. Neurosci. 36, 9303 9312. doi: 10.1523/JNEUROSCI.4452-15.2016

Yu, A. J., and Dayan, P. (2005). Uncertainty, neuromodulation, and attention. Neuron 46, 681-692. doi: 10.1016/j.neuron.2005.04.026

Yuan, T. F., and Hou, G. (2015). Commentary: oxytocin enables maternal behavior by balancing cortical inhibition. Front. Behav. Neuroscience 9:311. doi: 10.3389/ fnbeh.2015.00311

Yuille, M. B., Olmstead, C. K., Wells, A. K., and Hahn, B. (2017). A test of the cognitive-enhancing potential of low-dose mecamylamine in healthy non-smokers. Psychopharmacology 234, 109-116. doi: 10.1007/s00213-0164443-2

Zaborszky, L., Csordas, A., Duque, A., Somogy, J., and Nadasdy, Z. (2002). "Computational anatomical analysis of the basal forebrain corticopetal system," in Computational Neuroanatomy: Principles and Methods, ed. G. Ascoli (Totowa, NJ: Humana Press), 171-197.

Zaborszky, L., and Duque, A. (2003). Sleep-wake mechanisms and basal forebrain circuitry. Front. Biosci. 8:d1146-d1169.

Zaborszky, L., Duque, A., Gielow, M., Gombkoto, P., Nadasdy, Z., and Somogyi, J. (2015). "Organization of the basal forebrain cholinergic projection system: specific or diffuse?" in The Rat Nervous System, 4 Edn, ed. G. Paxinos (Amsterdam: Elsevier Inc), doi: 10.1016/B978-0-12-374245-2. 00019-X

Zaborszky, L., Gombkoto, P., Varsanyi, P., Gielow, M. R., Poe, G., Role, L. W., et al. (2018). Specific basal forebrain-cortical cholinergic circuits coordinate cognitive operations. J. Neurosci. 38, 9446-9458. doi: 10.1523/JNEUROSCI. 1676-18.2018

Zoghi, M., Pearce, S. L., and Nordstrom, M. A. (2003). Differential modulation of intracortical inhibition in human motor cortex during selective activation of an intrinsic hand muscle. J. Physiol. 550, 933-946. doi: 10.1113/jphysiol.2003. 042606

Conflict of Interest: The authors declare that the research was conducted in the absence of any commercial or financial relationships that could be construed as a potential conflict of interest.

Copyright (c) 2021 Lockhofen and Mulert. This is an open-access article distributed under the terms of the Creative Commons Attribution License (CC BY). The use, distribution or reproduction in other forums is permitted, provided the original author(s) and the copyright owner(s) are credited and that the original publication in this journal is cited, in accordance with accepted academic practice. No use, distribution or reproduction is permitted which does not comply with these terms. 